\title{
Effects of spatial elements and sound sources on sound field in Main Hall of Chinese Buddhist temple
}

\author{
Dongxu Zhang, ${ }^{1}$ Ruipeng Lai, ${ }^{1}$ Mei Zhang, ${ }^{2}$ and Jian Kang ${ }^{3, a)}$ \\ ${ }^{1}$ JangHo Architecture College, Northeastern University, Shenyang, 110819, China \\ ${ }^{2}$ School of East Asia Studies, University of Sheffield, Sheffield, S10 2TD, United Kingdom \\ ${ }^{3}$ Institute of Environmental Design and Engineering, The Bartlett, University College London, London WC1H ONN, United Kingdom
}

\begin{abstract}
:
In Chinese Han Buddhist temples, the Main Hall is the paramount indoor religious location, for which acoustic quality is very important for several Buddhist rites held within; however, the sound field in the Main Hall has not yet been analyzed scientifically. By combining sound field measurement with acoustic simulation, this study investigated the effects of spatial elements and sound source characteristics in a Main Hall, revealing that both fabric sound absorbers and Buddha statues mounted within had a pronounced effect on the sound field. Using an acoustic model of the Main Hall of the Xiantong Temple as an example, when various fabric sound absorbers were removed, the mid-frequency reverberation time $\left(T_{30 m}\right)$ and mid-frequency early decay time $\left(\mathrm{EDT}_{m}\right)$ increased by $32.3 \%$ and $46.8 \%$, respectively. When fabric sound absorbers and Buddha statues were removed, the sound pressure level was not significantly affected. The form of the roof did not significantly impact the indoor sound field. The directivity of the sound sources did not significantly affect the $T_{30 m}$ but did affect the $\mathrm{EDT}_{m}$ and the speech transmission index (STI). When monks chanted sutras face-to-face, the STI was maximized. Additionally, changing the positions of sound sources moderately affected the EDT and STI. (C 2020 Acoustical Society of America.

https://doi.org/10.1121/10.0000758
\end{abstract}

(Received 18 July 2019; revised 30 January 2020; accepted 31 January 2020; published online 6 March 2020)

[Editor: Francesco Martellotta]

Pages: $1516-1530$

\section{INTRODUCTION}

Han Buddhism has been practiced for more than 2000 years in China. Han Buddhist temples have provided not only good sites for the religious practice of monks and followers but also served as important public activity spaces in ancient China. ${ }^{1}$ Generally, favorable acoustic and visual environments play important roles in creating a religious atmosphere for temples, and have promoted the development and spread of Han Buddhism in China. ${ }^{2}$ Because of the influence of both China's traditionally ritual and Buddhist cultures, most Chinese Han Buddhist temples use an axisymmetric and multi-courtyard layout, as illustrated in Fig. 1. In a Han Buddhist temple, the largest and most important building is the Main Hall, which is located along the central axis of the temple and provides an important site for morning and evening chanting and religious rites. One consequence is that indoor acoustic quality plays a critical role in the acoustic environment of the temple. A traditional Main Hall is fitted with many religious ornaments and Buddha statues placed at the center and sides, which may affect the indoor sound field. For the ritual activities of Han Buddhism, indoor sound sources are arranged in a distinctive way that differs from those of other religions or nonreligious performance locations.

Many studies have focused on the influence of indoor sound fields in religious sites and performance locales. Analyzing indoor sound absorbers, Boren simulated and

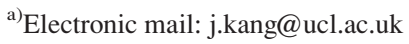

analyzed the indoor sound fields of two churches in Venice during festivals, and found that the reverberation time $\left(T_{30}\right)$, early decay time (EDT), and musical clarity (commonly expressed by " $C_{80}$," which is defined as the logarithmic ratio of early to late sound energy, where early refers to sound arriving in the first $80 \mathrm{~ms}$, and later refers to sound arriving after this period) improved significantly due to crowds of attendees, newly added seats, and wall ornaments, over their characteristics when unoccupied during ordinary periods. ${ }^{3}$ Navarro suggested that the wooden ceiling of an early Christian church had superior acoustic performance to the vaulted roof of a Romanesque church. ${ }^{4}$ Cirillo showed that churches with a vaulted nave produce considerably longer reverberation times, whereas a wooden ceiling with painted canvases causes a significant reduction in the reverberation time, particularly for middle and low frequencies. ${ }^{5}$ Comparable research has shown that the addition of strips of polyester fiber to pew seats contributes to increased absorption. ${ }^{6}$ Alonso showed that suspended textile materials induce a significant effect on the reverberation time in a church, mainly at an intermediate frequency. ${ }^{7}$

Research into lightweight tapestries hung vertically has shown that different levels of sound absorption may be obtained by simply changing the distance of the tapestries from walls. ${ }^{8}$ Total sound absorption is better related to the number of persons present than to the area covered. ${ }^{9}$ Experimental results have shown a dependence on occupation density, posture, and the thermal resistance of clothing, leading to the definition of a series of equations to predict 


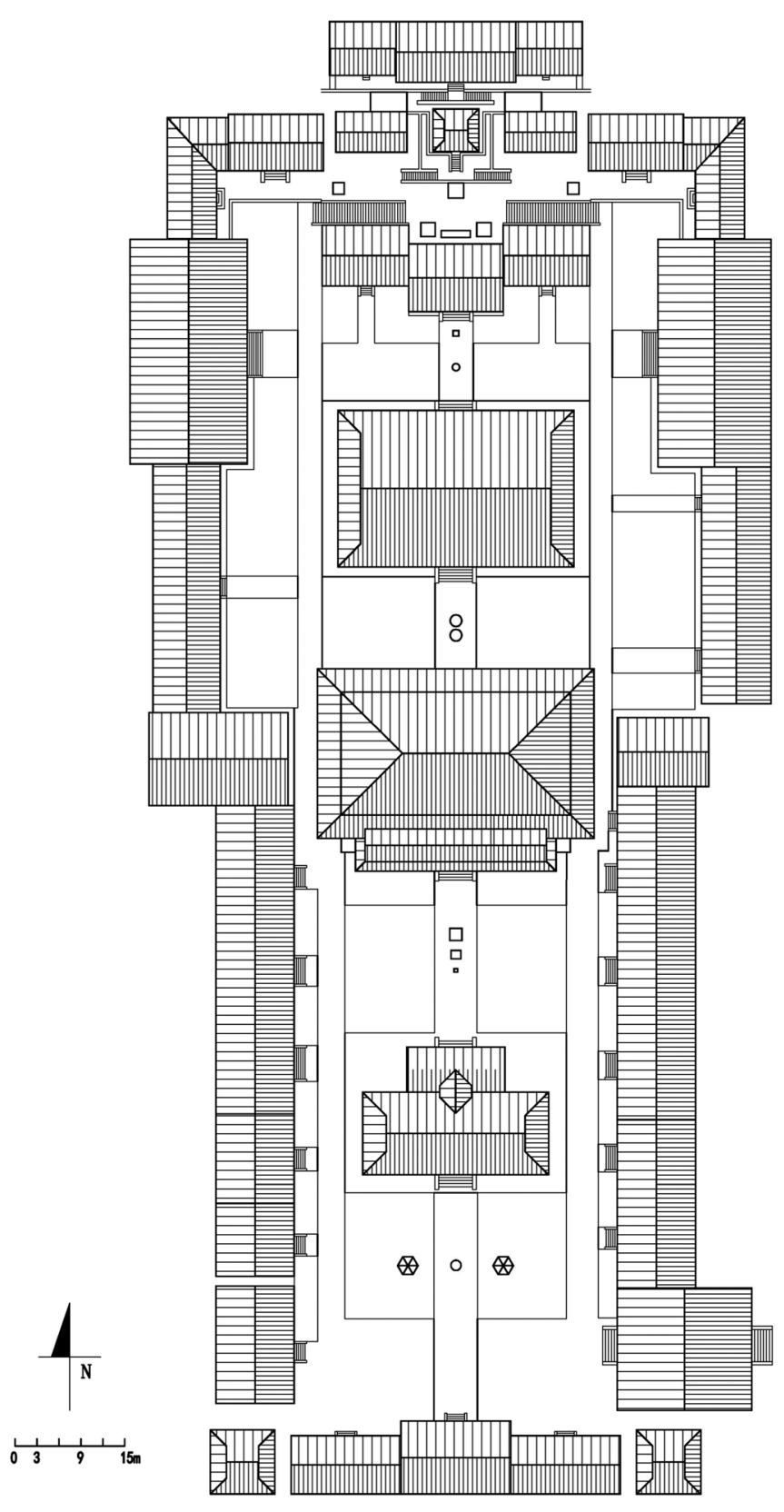

FIG. 1. Site plan of the Xiantong Temple in Mount Wutai.

absorption coefficients as functions of frequency. ${ }^{10}$ The correlation between sound field parameters and church materials has also been studied via an analysis of several Roman churches. ${ }^{11}$ Acoustic measurements were performed in six churches to compare and analyze the intelligibility of speech in occupied and unoccupied rooms. ${ }^{12}$ Girón et al. summarized the principal contributions to the acoustics of ancient occidental Christian churches in recent decades. ${ }^{13}$

Studies of indoor sound diffusers have shown that they absorb a portion of the sound energy, resulting in a decrease in the sound pressure level (SPL), which is not easily noticeable, and while diffusion contributed to early reflections and enhanced speech intelligibility. ${ }^{14}$ Surface decorations, such as balconies and coffered ceilings in old halls, can produce a highly diffuse and blended sound experience, which is the acoustic hallmark of a traditional concert hall. ${ }^{15}$ Diffusers can be used to maintain ambiance, promote even scattered energy coverage, improve spaciousness, and remove echoes. ${ }^{16}$ Further, spatial shapes can affect sound fields in religious sites, and in a study varying the dimensional ratios of 25 box-shaped churches, Berardi evaluated the dependence of building shape and acoustics, proposing that the length-towidth ratio has a significant influence on the values of both $C_{80}$ and the center time (Ts). ${ }^{17}$ More subjectively, Carvalho found that a feeling of intimacy is related to church volume. ${ }^{18}$ Using an in situ measurement and a simulation, Indian researchers analyzed the sound field characteristics of one of the large hollow Buddhist Stupas in a Buddhist temple in Nagpur and obtained the average reverberation times of the Stupa at mid-frequencies. They were 5.6 and $9.7 \mathrm{~s}$ for occupied and unoccupied conditions, respectively. Note, the midfrequency result is the average of values in the bands of 500 and $1000 \mathrm{~Hz}$, and denoted by subscript " $m$ " in this paper. Then, the effects of these characteristics on religious activities were investigated (e.g., Buddhist chanting). ${ }^{19}$ Further, Sato and Koyasu conducted model room experiments to investigate the effect of the shape and size of a room on its sound field and presented that fluctuations of the reverberation time became small for irregular rooms when compared with those of rectangular rooms. ${ }^{20}$

A number of studies have also looked at the directivity and location of sound sources in religious sites. By simulating several churches, Alvarez-Morales analyzed the effects of different sound source locations on music clarity and speech intelligibility. ${ }^{21}$ Speech intelligibility decreased in all of the churches when the priest turned his back to the audience compared with when he faced the audience. ${ }^{22}$ Through acoustic measurements, Japanese researchers found that changes in the location and directivity of sound sources during chanting affected the speech transmission index (STI) and interaural cross-correlation coefficient (IACC) of the sound field in a temple. ${ }^{23}$ In Japanese churches, changes in the direction could improve the intelligibility of speech. By contrast, source location had relatively little effect on acoustic parameter values. ${ }^{24}$

Previous studies of the acoustic environments and sound fields in Han Buddhist temples have primarily concentrated on the musicological aspects of Buddhist music and bell sounds. ${ }^{25-28}$ Recently, studies have attempted to analyze and interpret the acoustic environments of Han Buddhist temples by focusing on sound characteristics and soundscape. For example, Ge et al. investigated the acoustic environment of the Jingci Temple near West Lake through measurements and a questionnaire. ${ }^{29}$ Zhang et al. studied the temple's environmental quietness and soundscape, along with respective subjective and objective influencing factors, and analyzed sound preferences in Han Buddhist temples, arguing that evaluations of acoustic environments and sounds are affected by respondents' personal characteristics (e.g., religious beliefs). ${ }^{2,30,31}$

Generally, however, few studies have investigated the sound field characteristics and acoustic factors of the indoor 
spaces of Main Halls in Han Buddhist temples. Even if traditional field measurements can be used to investigate basic acoustic parameters of a traditional Main Hall, their sound fields have varying scales and layouts, making characterization difficult. Moreover, traditional Main Halls are strictly protected as historical buildings, and alteration of the facilities and layouts of their indoor spaces is not allowed. This compounds the difficulty of making field measurements in order to characterize their sound fields adequately.

This study investigates the effects of spatial elements and sound source characteristics on the sound field in the Main Hall of a Han Buddhist temple. The effects of indoor sound absorbers and diffusers, roof shapes, and the locations and directivity of indoor sound sources on the sound field are studied. The absorption and scattering coefficients of the traditional materials enclosing the indoors were examined through field measurement and simulation, and then an acoustic model of a typical Main Hall in a Han Buddhist temple was built. Finally, variation in the sound field was analyzed by changing the spatial elements or the directivity and locations of sound sources in the model.

\section{METHODS}

\section{A. Measured objects}

To date, few studies have investigated the acoustic characteristics of traditional Chinese building materials such as their absorption and scattering coefficients. It is also difficult to carry out universally applicable studies under laboratory conditions. To ensure the accuracy of the acoustic simulations of Main Halls, simulation data were compared and adjusted with field measurement data to determine simulated absorption and scattering coefficients of building materials. In Han Buddhist temples, which are places of religious practice, acoustic measurement is basically not allowed. The Buddha statues and fabric Buddhist ornaments could not be removed at random. Thus, it was impossible to adopt conventional methods for the field measurement. ${ }^{32}$ Therefore, three great halls of the Shenyang Imperial Palace that share the same architectural style and materials as traditional Han Buddhist temples were selected for acoustic test and simulation. As a world cultural heritage site, the Shenyang Imperial Palace was originally built in 1625 and is the largest ancient building complex in Northeast China. To conduct an indoor sound field test, the three most representative halls were selected: Chongzheng Hall (the building has a flush gable roof, an interior volume of $\sim 1610 \mathrm{~m}^{3}$ with a ridge $11.85 \mathrm{~m}$ high, and a floor $20.5 \mathrm{~m}$ long and $11 \mathrm{~m}$ wide), Qingning Hall (the building has a flush gable roof, an interior volume of $\sim 1110 \mathrm{~m}^{3}$ with a flat suspended ceiling $5.5 \mathrm{~m}$ high, and a floor $17 \mathrm{~m}$ long and $11.9 \mathrm{~m}$ wide), and Dazheng Hall (the plane is a regular octagon, $5.4 \mathrm{~m}$ on each side, the interior volume is $\sim 1370 \mathrm{~m}^{3}$ with a suspended ceiling average about $10.3 \mathrm{~m}$ high). At present, these three halls are intact, and their indoor facilities were restored to their original state during the Qing Dynasty. ${ }^{33,34}$ Chongzheng
Hall is the most important building in the Shenyang Imperial Palace. As illustrated in Fig. 2(a), it has no suspended ceiling but an exposed pitched roof. Figure 2(b) illustrates a measured floor plan and the layout of the acoustic receivers.

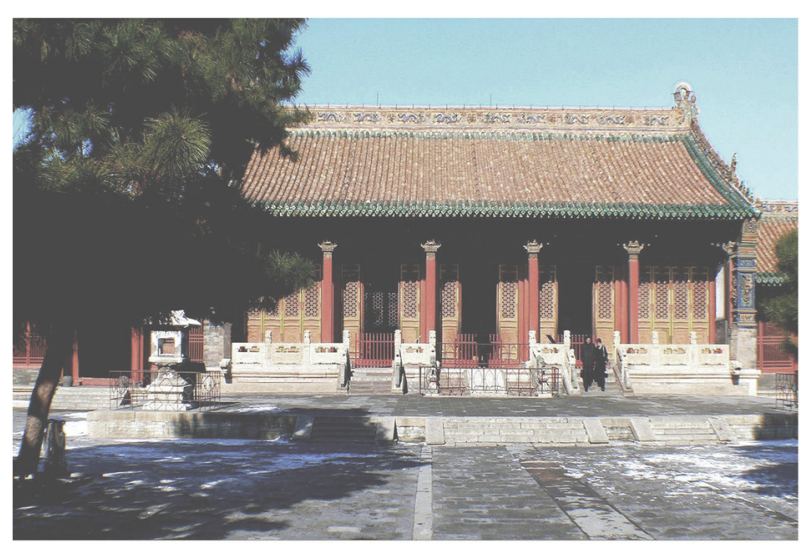

Exterior view of Chongzheng Hall.

(a)

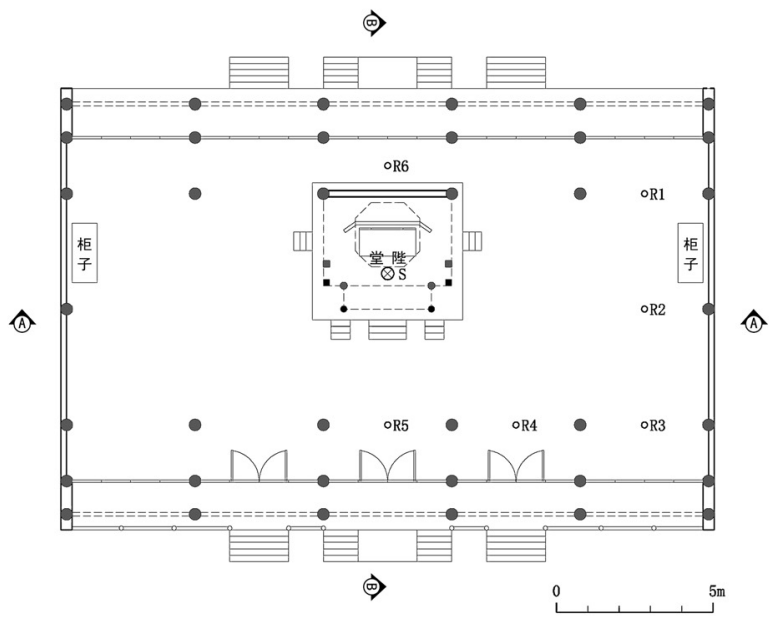

Floor plan of Chongzheng Hall and layout of sound sources and receivers.

(b)

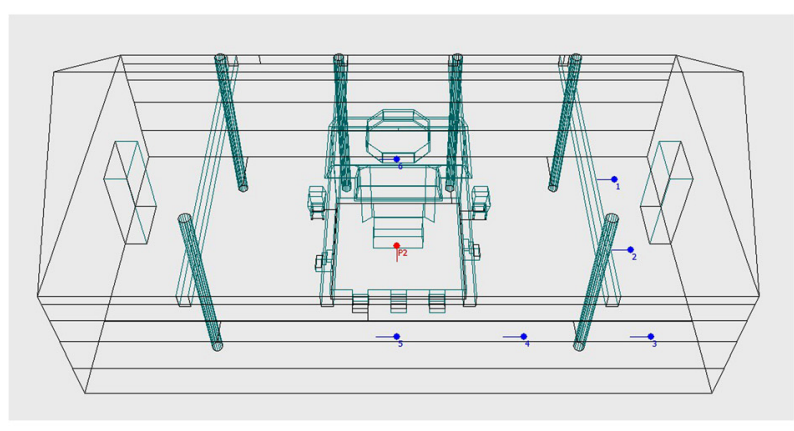

Acoustic model of Chongzheng Hall.

(c)

FIG. 2. (Color online) Current actual layout and acoustic model of Chongzheng Hall, including the (a) exterior view, (b) floor plan and layout of sound sources and receivers, and (c) acoustic model. 


\section{B. Measurement process}

The deployed instruments included a dodecahedral sound source, sound level meters, and real-time signal analyzers. The sound level meters were calibrated beforehand to control error to less than $0.3 \mathrm{~dB}$. The acoustic parameters measured were the reverberation time and SPL. Sound fields were measured from 06:30 to 08:00 and from 17:30 to 20:00, when the three halls were unoccupied and the environment was relatively quiet. The measurement process basically followed the international standard ISO 3382-1. One $1.5 \mathrm{~m}$ high dodecahedral sound source was placed at the center of each hall. In each hall, 5-6 receivers were set up. The receivers were positioned at least $2 \mathrm{~m}$ apart. The distance from any receiver to the nearest reflecting surface was at least $1 \mathrm{~m}$. The measurement of reverberation time used the interrupted noise method, that is, the source produced $100 \mathrm{~dB}$ (or higher) pink noise that continued for more than $5 \mathrm{~s}$. After the sound field had achieved a steady state, the source was switched off. Then, one $1 \mathrm{~m}$ high signal receiver was used to record sound attenuation, and the reverberation time in each receiver was calculated within a spectral range of $125 \mathrm{~Hz}-4 \mathrm{kHz}$. The ISO 3382-1 standard requires that the source level provides at least $45 \mathrm{~dB}$ above the background level in the corresponding frequency band. Therefore, the background noises in the three halls were measured repeatedly before the reverberation time and SPL measurement. The results showed that the maximum background noise level was less than $25 \mathrm{~dB}$ at each frequency, thereby satisfying the requirement. When measuring the SPL, the source also produced a continuous $100 \mathrm{~dB}$ (or higher) sound, and the SPL at each receiver was recorded. To reduce measurement errors, the SPL and reverberation time of each receiver were measured at least three times, and their averages were used. The measurement processes were essentially the same between the three halls. Figure 3(a) illustrates the results of $T_{30}$ measurements at various points in Chongzheng Hall. Figure 3(b) illustrates the measured average of $T_{30}$ in the three halls.

Note that two source positions were used in the measurement process for each great hall. However, in the three great halls, the average difference of the two sets of reverberation time data in each frequency band was less than $5 \%$. In order to simplify the research process, measurements using the second source are not listed or used in the paper. Also note, during measurements, the receivers were placed at a height of $1 \mathrm{~m}$ rather than $1.2 \mathrm{~m}$ as suggested by ISO 3382-1. A major consideration was that the receiver was at the same height as the ears of the ministers when they knelt on the ground to listen to the emperor's speech in the great halls of the Shenyang Imperial Palace.

\section{Simulation verification process}

In this study, acoustics were simulated with ODEON13.02, a software package originally developed by the Technical University of Denmark in 1984. By combining the image source, ray-tracing, and secondary sources

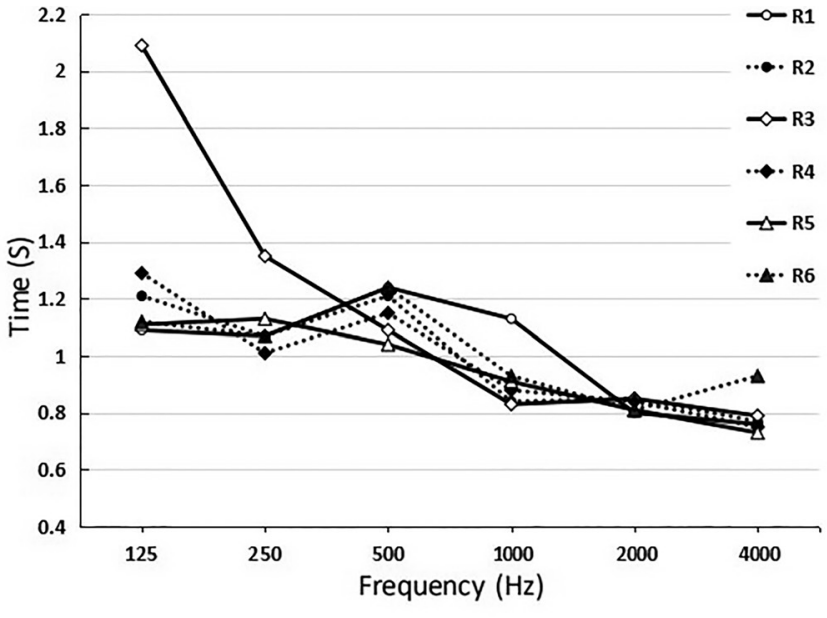

The results of $T_{30}$ measurements at various points in Chongzheng Hall.

(a)

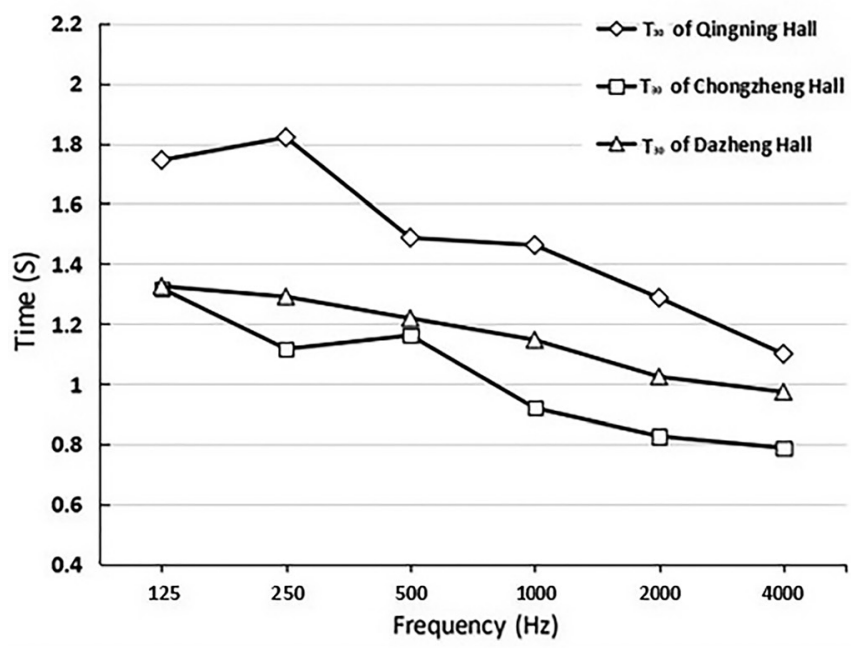

The measured average values of $T_{30}$ in three halls.

(b)

FIG. 3. The results of $T_{30}$ measurements in the three halls. (a) The results of $T_{30}$ measurements at various points in Chongzheng Hall. (b) The measured average values of $T_{30}$ in three halls.

methods, ODEON13 was used to conduct a computerized acoustic simulation for the absorption, scattering, and diffraction of sound waves, thus, providing comprehensive reference data for acoustic analysis. ${ }^{35,36}$ In the process of this simulation, the software calculation settings were set to the most accurate mode: "precision." Quick and global estimate functions were used to estimate the reverberation time of the acoustic models. There were two important parameters in the general setting of ODEON13: "impulse response length" and "number of late rays." The former was advised to be two-thirds of the longest estimated reverberation time, while the latter initially adopted the value automatically assigned by the software, and then repeatedly adjusted and gradually increased until the calculated reverberation time was roughly stable. Other parameters were set according to the user manual recommendations. For example, transition 
order was set to two and the interior margin was set to $0.1 \mathrm{~m}$, with this parameter being directly correlated with model fitness.

The acoustic model for the Main Hall, first built with Google Sketchup 2015 (California, USA), was fed to ODEON13. The architectural components of ancient Chinese buildings, such as the bucket arch and roof, are very complex. Therefore, the acoustic model was simplified somewhat during modeling. In this study, threedimensional (3D) models were built for the three halls using their dimensional measurements, and corresponding sound sources and receivers were set up in the 3D models according to the acoustic measurements. Figure 2(c) illustrates the sound field model for Chongzheng Hall.

For acoustic simulation, the key acoustic parameters of the materials were the absorption and scattering coefficients. Here, the absorption coefficient of the traditional building materials was initially set according to the acoustic parameters of similar materials cited from references in the acoustics literature, ${ }^{37-41}$ and those absorption coefficients should be accurate because they were obtained from multiple experiments and verified by numerous studies. The scattering coefficient was set by observation of the outer surface condition of the materials and the simplicity of the acoustic model. Then, the simulated values of $T_{10}$ (the reverberation time extrapolated from the time required for sound to decay by $10 \mathrm{~dB}$, from $-5 \mathrm{~dB}$ to $-15 \mathrm{~dB}), T_{30}$, and $\mathrm{SPL}$ of the acoustic model were compared to match the field measurements of the three halls. That is, according to the difference of reverberation time and SPL between measurement and simulation of each receiver, the scattering coefficients of the primary materials (those with large surface area such as brick wall, bluestone ground, roof, and so on) and secondary materials (those with small surface area such as glass window, wooden door leaf, Carven wooden screen, and so on) were initially adjusted moderately. If the difference was not narrowed, the sound absorption coefficient of primary and secondary materials was replaced by another set of similar materials from the acoustics literature. After several adjustment cycles, approximate values of the acoustic absorption and scattering coefficients of the common materials in the ancient Chinese buildings were determined. Three halls were selected to measure and simulate their sound fields, and to cross-verify their results, ensuring the accuracy and universality of the simulation.

Table I lists the approximate values of the acoustic absorption and scattering coefficients of various indoor materials that were determined by using the method described above. Figure 4 illustrates the differences between the simulated acoustic values based on the coefficients of Table I and the measured sound-field values. For most SPLs, the differences for each frequency range from $-5 \mathrm{~dB}$ to $5 \mathrm{~dB}$, with differences in the middle frequencies mostly ranging from $-3 \mathrm{~dB}$ to $3 \mathrm{~dB}$. For most reverberation times, the ratio of the difference between the simulated and measured $T_{30}$ to the measured $T_{30}$ ranged from $-20 \%$ to $20 \%$, and from $-10 \%$ to $10 \%$ for middle frequencies, and the $T_{10}$ verification result is similar to that of $T_{30}$. In general, errors were lower for middle and high frequencies than for low frequencies. Our simulation accuracy had not entirely met the common acoustic criteria, which requires the simulated error be less than the just noticeable differences (JND) of this parameter. However, we consider the errors in this study to be within an acceptable range for the following reasons. There were complexities, including poor spatial closedness of the indoor sound field, a lack of related research such that no standard acoustic parameters of materials in ancient Chinese architecture could been used for reference, and those ancient building materials and Buddhist ornaments could not be removed for measurement in an acoustic laboratory. In addition, the purpose of this research was mainly to analyze the influence of the various sound absorbers and Buddha statues on the sound field rather than to obtain actual acoustic parameters.

In this simulation and verification process for characterizing the sound fields, the following points should be noted:

TABLE I. Acoustic absorption and scattering coefficients of indoor materials in the acoustic model of the halls.

\begin{tabular}{|c|c|c|c|c|c|c|c|}
\hline \multirow[b]{2}{*}{ Material } & \multicolumn{6}{|c|}{ Acoustic absorption coefficient under following frequencies $(\mathrm{Hz})$} & \multirow[b]{2}{*}{ Scattering coefficient } \\
\hline & 125 & 250 & 500 & 1000 & 2000 & 4000 & \\
\hline Ordinary window glass (Ref. 37) & 0.35 & 0.25 & 0.18 & 0.12 & 0.07 & 0.04 & 0.10 \\
\hline Plastered brick wall (Ref. 37) & 0.013 & 0.015 & 0.02 & 0.03 & 0.04 & 0.05 & 0.05 \\
\hline Plain brick wall (Ref. 37) & 0.03 & 0.03 & 0.03 & 0.04 & 0.05 & 0.07 & 0.05 \\
\hline Indoor hardwood material (Ref. 39) & 0.05 & 0.05 & 0.05 & 0.05 & 0.05 & 0.05 & 0.05 \\
\hline Roof (without suspended ceiling; Ref. 40) & 0.25 & 0.40 & 0.50 & 0.55 & 0.60 & 0.60 & 0.50 \\
\hline Roof (with flat suspended ceiling; Ref. 40) & 0.16 & 0.15 & 0.10 & 0.10 & 0.10 & 0.10 & 0.40 \\
\hline Wooden door leaf (Ref. 39) & 0.16 & 0.15 & 0.10 & 0.10 & 0.10 & 0.10 & 0.20 \\
\hline Carpet (Ref. 39) & 0.13 & 0.22 & 0.33 & 0.46 & 0.59 & 0.53 & 0.10 \\
\hline Carven wooden screen (Ref. 40) & 0.14 & 0.22 & 0.36 & 0.32 & 0.28 & 0.22 & 0.40 \\
\hline Bucket arc (Ref. 38) & 0.32 & 0.47 & 0.51 & 0.58 & 0.62 & 0.63 & 0.50 \\
\hline Bluestone ground (Ref. 37) & 0.01 & 0.01 & 0.015 & 0.02 & 0.02 & 0.02 & 0.05 \\
\hline Curtain (Ref. 41) & 0.11 & 0.32 & 0.54 & 0.64 & 0.55 & 0.70 & 0.25 \\
\hline Buddha statue and backlight (Ref. 40) & 0.14 & 0.22 & 0.36 & 0.32 & 0.28 & 0.22 & 0.60 \\
\hline Light textile cushion (Ref. 39) & 0.33 & 0.55 & 0.64 & 0.58 & 0.61 & 0.58 & 0.05 \\
\hline
\end{tabular}




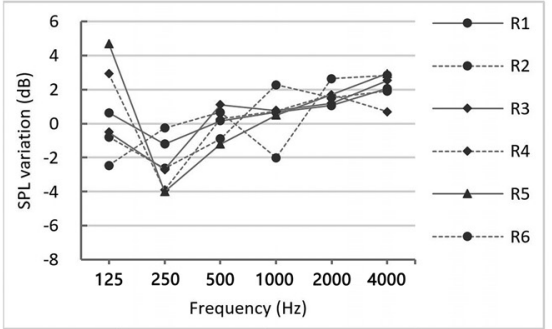

Differences in SPL of Chongzheng Hall.

(a)

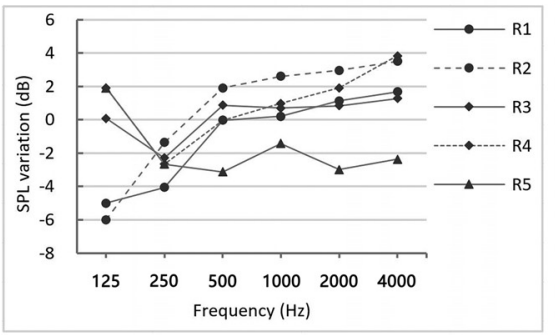

Differences in SPL of Dazheng Hall.

(d)

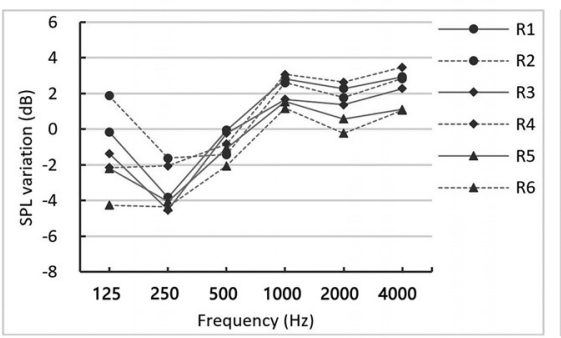

Differences in SPL of Qingning Hall.

(g)

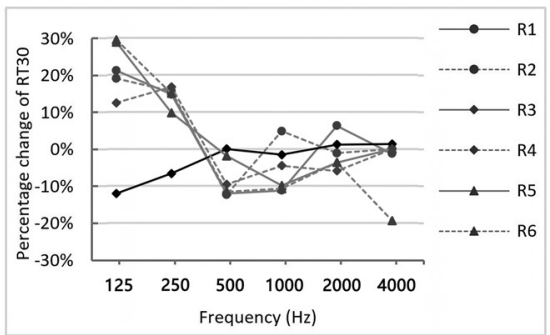

Percentage differences in $T_{30}$ of Chongzheng Hall.

(b)

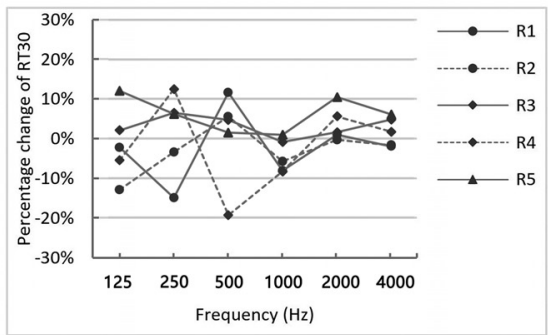

Percentage differences in $\mathrm{T}_{30}$ of Dazheng Hall.

(e)

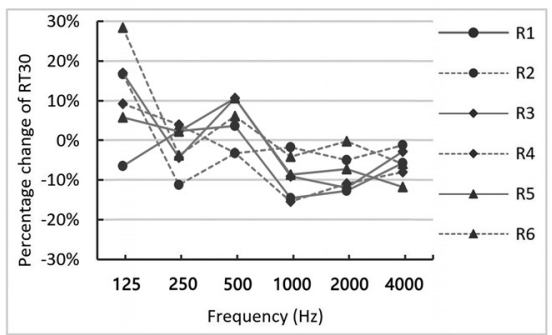

Percentage differences in $T_{30}$ of Qingning Hall.

(h)

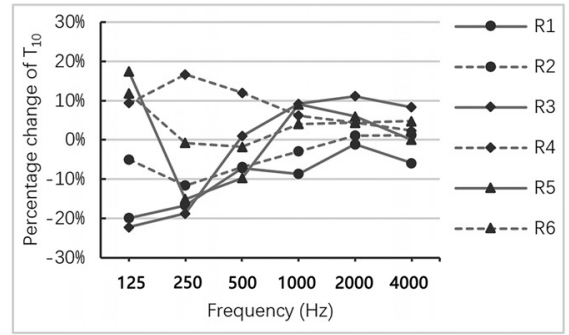

Percentage differences in $\mathrm{T}_{10}$ of Chongzheng Hall.

(c)

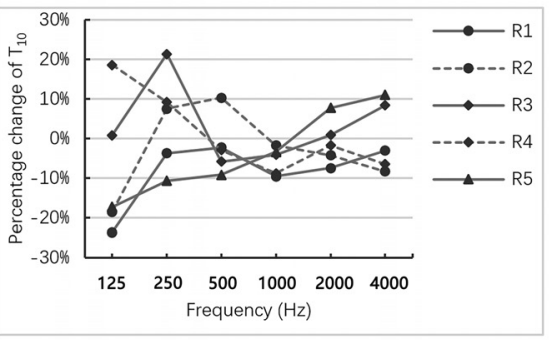

Percentage differences in $T_{10}$ of Dazheng Hall.

(f)

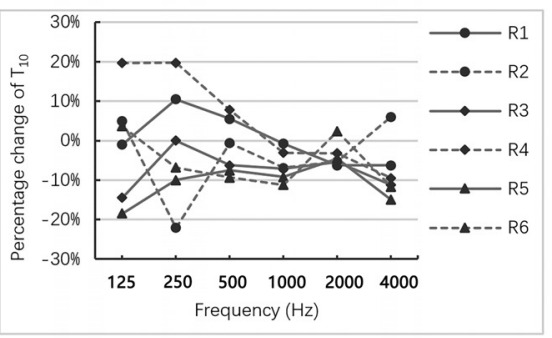

Percentage differences in $T_{10}$ of Qingning Hall.

(i)

FIG. 4. Differences in SPL and percentage differences in reverberation time between measured and simulated results in three halls. (a) Differences in SPL of Chongzheng Hall. (b) Percentage differences in $T_{30}$ of Chongzheng Hall. (c) Percentage differences in $T_{10}$ of Chongzheng Hall. (d) Differences in SPL of Dazheng Hall. (e) Percentage differences in $T_{30}$ of Dazheng Hall. (f) Percentage differences in $T_{10}$ of Dazheng Hall. (g) Differences in SPL of Qingning Hall. (h) Percentage differences in $T_{30}$ of Qingning Hall. (i) Percentage differences in $T_{10}$ of Qingning Hall.

(1) The interiors of ancient Chinese buildings are intricate and complex, thus, we have made appropriate simplifications in the acoustic models. As a result, the absorption and scattering coefficients for some materials in the sound field simulation did not completely agree with their acoustic characteristics. However, when those parameters were applied together in an acoustic model, the results of the sound field simulation were made as consistent as possible with the measurements. The absorption and scattering coefficients of the materials in Table I are applicable only to the acoustic models built in this study or indoor acoustic models of similar dimensions for Chinese ancient buildings.

(2) The frequencies of human languages are dominated by middle frequencies. In particular, chanting by monks is concentrated in a range from 100 to $500 \mathrm{~Hz} .{ }^{42}$ While some Buddhist instruments contained middle and high frequencies. Considering this, the chanting and accompaniment of musical instruments were the primary sound sources in the Main Halls. The middle frequencies were chosen as representative data to simplify the research process. When adjusting and fitting the simulated results, this study ensured that average values of the middle frequencies approximated the measured results as much as possible. The subsequent comparative analysis primarily focuses on data from these frequencies.

\section{Spatial and layout characteristics of a Main Hall}

A traditional Main Hall is often constructed with a wooden framework that is enclosed by brick, stone, or plank walls, and is rectangular and fitted with various forms of sloping roofs (e.g., flush gable, gable-and-hip, or hip). Depending on the size of the temple, a traditional Main Hall is composed of 3-11 standard widths. Its interior space can be divided into spaces for the Buddha and worship. Typically, one, three, five, or seven Buddha statues are mounted. The central Buddha statues are large, and those that are centrally placed tend to be furnished with fanshaped backlights. The side Buddha statues, such as the Eighteen Arhats, are also placed along both gable walls. Some Main Halls do not have suspended ceilings, whereas others are fitted with flat suspended ceilings to ensure the regularity of the indoor space. Main Halls have many cloth 
Buddhist ornaments, including canopies with streamers above the Buddha, curtains over a cylindrical frame, pennants, long narrow flags, and cushions for kowtowing and praying on the ground. Such textile ornaments originated in the times of Buddha Sakyamuni and are intended to highlight the religious atmosphere inside Buddhist buildings and create an ideal space for Buddhist practices. In addition, the ornaments function as sound absorbers. Ancient Chinese knew that sound-absorbing curtains and flags could be suspended in various performance areas to reduce the reverberation time and improve indoor acoustic quality. ${ }^{42}$

Monks and followers in a Main Hall are usually both sound producers and receivers. Chanting is a primary sound source, a combination of speaking and singing by monks, and is accompanied by sounds generated by Buddhist musical instruments. The worship space typically faces the Buddha statues directly. At the center of the worship space is an offering table. During worship activities, monks and followers often lie on both sides of the offering table, but sometimes stand in rows and face the Buddha statue, kneel to chant sutras, or, occasionally, the monks on both sides of the offering table turn toward it and stand face-to-face to chant sutras. These layouts and behaviors would affect the sound field in a Main Hall.

\section{E. Building a sound field model of a Main Hall}

For the indoor sound field model of a Main Hall built in this study, the size of the building, height of the Buddha statues, and indoor layout were based on the Main Hall of the Xiantong Temple, the largest temple on Mount Wutai, which is one of China's four Buddhist holy mountains, as illustrated in Fig. 5(a). This Main Hall has a double-eave gable-and-hip roof. The indoor space spans seven standard widths with planar dimensions $35.2 \mathrm{~m} \times 25.5 \mathrm{~m}$ and an interior volume of approximately $5325 \mathrm{~m}^{3}$. The ridge is $17.6 \mathrm{~m}$ high, and the Main Hall is fitted with a flat suspended ceiling. Three central indoor Buddha statues are $4.8 \mathrm{~m}$ high, while the fan-shaped backlight is $6.7 \mathrm{~m}$ tall. The three central Buddha statues are all placed on a $1.9 \mathrm{~m}$ high altar, and nine Arhat statues are mounted on each of the two sides of the Main Hall against the gable walls. Around the central Buddha statues are Buddhist decorations, such as canopies, pennants, and long narrow flags, as illustrated in Fig. 5(b).

In the sound field model, eight receivers were set up in a grid $(2.5 \mathrm{~m} \times 3.5 \mathrm{~m})$ in the worship area on each side of the two offering tables. The receivers were distributed across the chanting area of the monks and bypass pillars and located more than $2 \mathrm{~m}$ away from building boundaries and pillars. This is indicated by points $r 1-r 8$ on the left side of the floor plan in Fig. 5(c). The receivers were placed $1.2 \mathrm{~m}$ above the ground, simulating the ear height of listeners who knelt on the kowtow cushions during religious rites.

To simulate and analyze the indoor sound field of the Main Hall, two types of sound sources were set. To analyze various acoustic parameters, such as the $T_{30}$ and SPL at different indoor locations, a nondirectional sound source

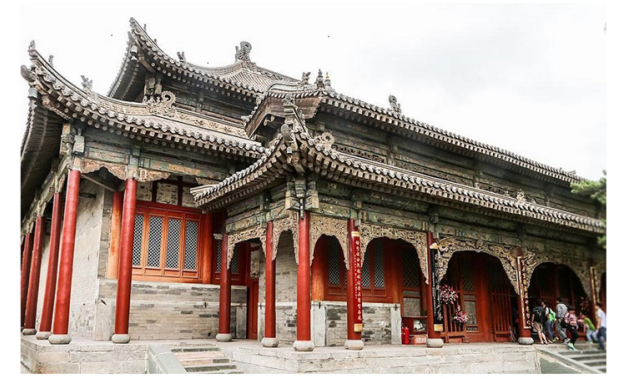

Exterior view of the Main Hall of Xiantong Temple in Mount Wutai.

(a)

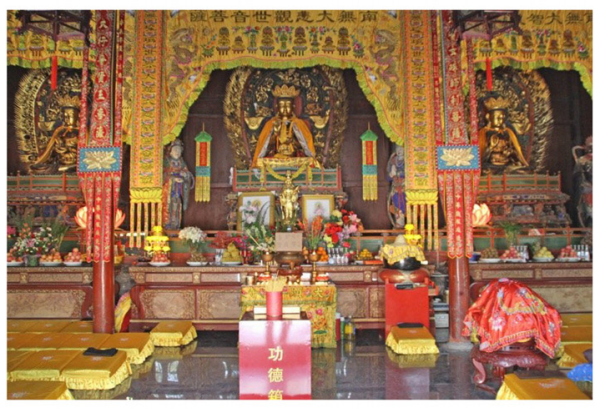

Interior view of the Main Hall of Xiantong Temple.

(b)

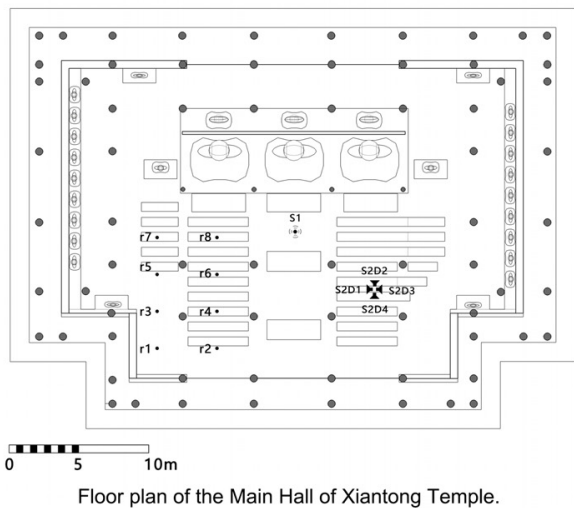

(c)

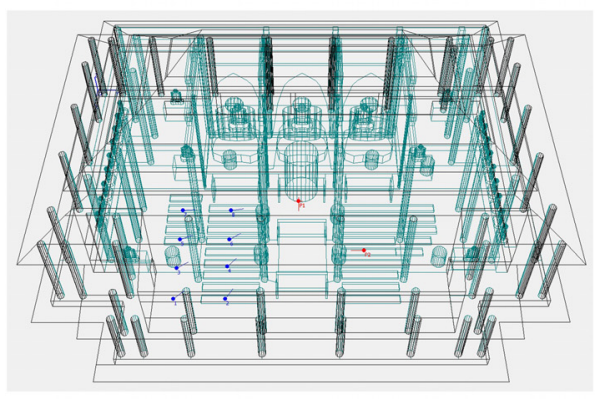

Acoustic model for the Main Hall of Xiantong Temple.

(d)

FIG. 5. (Color online) Main Hall of the Xiantong Temple on Mount Wutai, including the (a) exterior view, (b) interior view, (c) floor plan, and (d) acoustic model.

denoted S1 was placed $1.5 \mathrm{~m}$ high. It was placed in front of the altar to simulate the sonata sounds generated by lead monks when chanting, as well as various Buddhist musical instruments during religious rites such as morning and evening chanting. Previous studies have shown that sound directivity can affect the acoustic environment in temples. ${ }^{23}$ 
During worship activities in the Buddhist Main Hall, the general monks often change direction while chanting. To simulate this situation, a directional sound source $S 2$ was set up in the chanting area of the monks on the other side of the offering table, as illustrated in Figs. 5(c) and 5(d), to analyze the variation in the sound field in four directions:

(1) S2D1: toward the receivers, where monks on both sides stood face-to-face and chanted sutras, a common layout when chanting;

(2) S2D2: toward the central Buddha statues;

(3) S2D3: toward the side Buddha statues on the nearest gable wall with the sound source backed against the receivers;

(4) S2D4: toward the front door of the Main Hall.

This simulated the manner in which different sound source directions affected the sound field in the Main Hall. Figures 6(a) and 6(b) illustrate a comparison of the directivity from the directional sound source S2D2 and that from a human mouth; their characteristics are largely similar. Figure 6 also illustrates that the backward sound pressure of the directional sound source S2 decreases as the frequency increases. Another nondirectional sound source, denoted S3, was placed at the same position as S2 to compare the effect of sound source location on the sound field. Sound source S2 differed in directional characteristic, but was consistent with S1 and S3 in height and sound power level.

To set the power levels of these three sound sources, chanting sounds were generated by multiple people and accompanied by Buddhist musical instruments. This sound was recorded with an acoustic recorder at a position near the sound sources during morning chanting in the Xiangguo Temple of Kaifeng City. During chanting, no electroacoustic amplifier was used, and eight SPL values were recorded within a frequency range of $63 \mathrm{~Hz}-8 \mathrm{kHz}: 77.8,54.1,55.7$, $56.4,47.8,39.5,34.9$, and $13.7 \mathrm{~dB}$. Because the simulated results of the indoor sound field parameters were to be compared to one another, it was acceptable to use these SPL values as the sound power levels of the sound sources under different frequencies.

The acoustic model for the Main Hall of the Xiantong Temple used the absorption and scattering coefficients of the interface materials listed in Table I. Accordingly, the simulated indoor reverberation time was calculated and compared with its measured value. The reverberation time measurement in the Main Hall of the Xiantong Temple was based on the integrated impulse response method because the interrupted noise method was prohibited in this temple. A balloon burst was used as the impulse source. Note that the measured values of EDT or $T_{30}$ at $125 \mathrm{~Hz}$ varied greatly. This may have been due to the lack of low frequency energy in the balloon burst. Deemed as unreliable, we dismissed this data. As illustrated in Fig. 7, the differences between the values were small. Specifically, the values were similar to each other in the 500,1000, and $2000 \mathrm{~Hz}$ bands with the percent relative error for $T_{30}$ and EDT less than $10 \%$. This study focuses on analyzing mid-frequency data to assess the

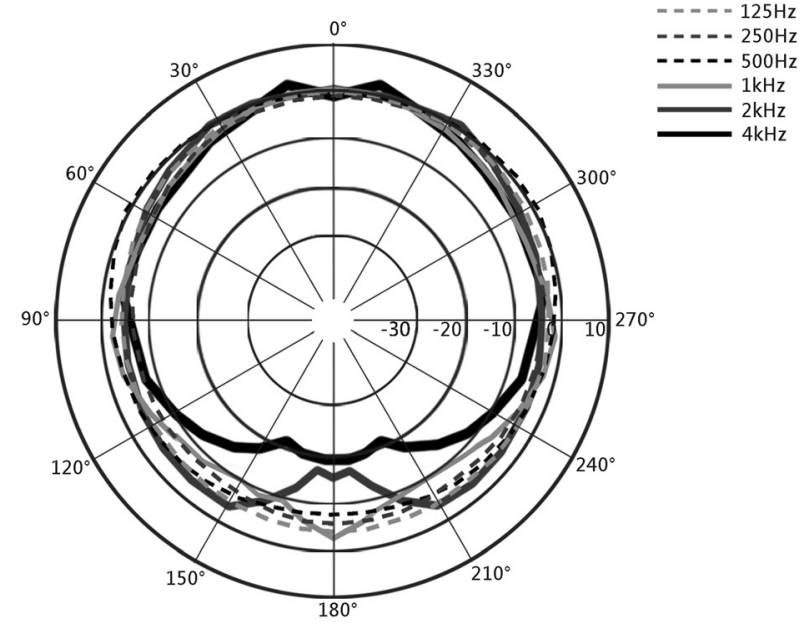

Distribution of sound pressure radiated from S2D2.

(a)

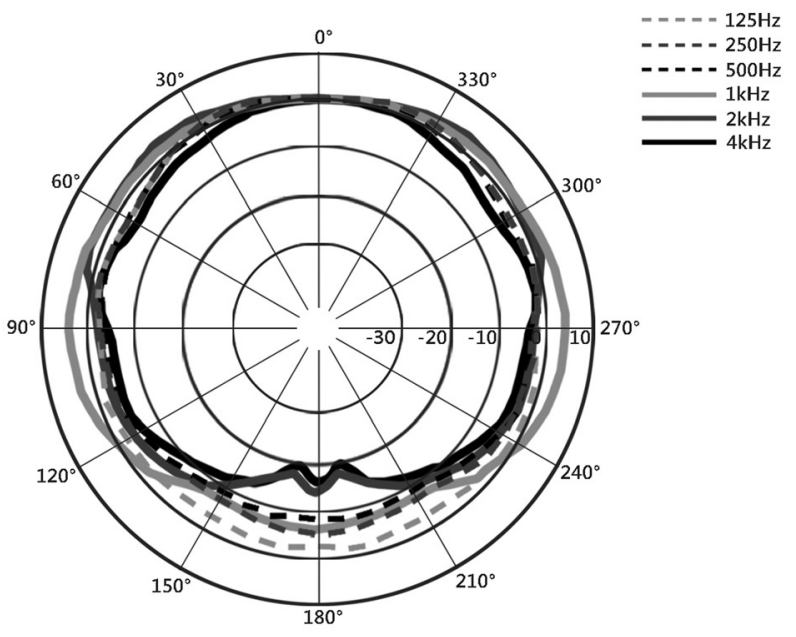

Distribution of sound pressure radiated from a human mouth. 24,43

(b)

FIG. 6. Directivity of sound sources in the horizontal plane.(a) Distribution of sound pressure radiated from S2D2. (b) Distribution of the sound pressure radiated from a human mouth (Refs. 24, 43).

influence of various spatial elements on the sound field in the Buddhist Main Hall. Thus, this acoustic model should be sufficient for the following study.

\section{F. Evaluation parameters for the sound field of the Main Hall}

In this study, the averages of calculated results from eight receivers were used as the parameter values for the sound field in the Main Hall. An $A$-weighted sound pressure level $[\operatorname{SPL}(A)]$ was selected because it is similar to human auditory ability, while averaged sound levels under midfrequencies $\left(\mathrm{SPL}_{m}\right)$ between the eight receivers were also compared. Typically, humans can distinguish a SPL change of $1 \mathrm{~dB}$, and a SPL change of $3 \mathrm{~dB}$ or higher is very apparent. Values of the $T_{30}$ and EDT were used for the 


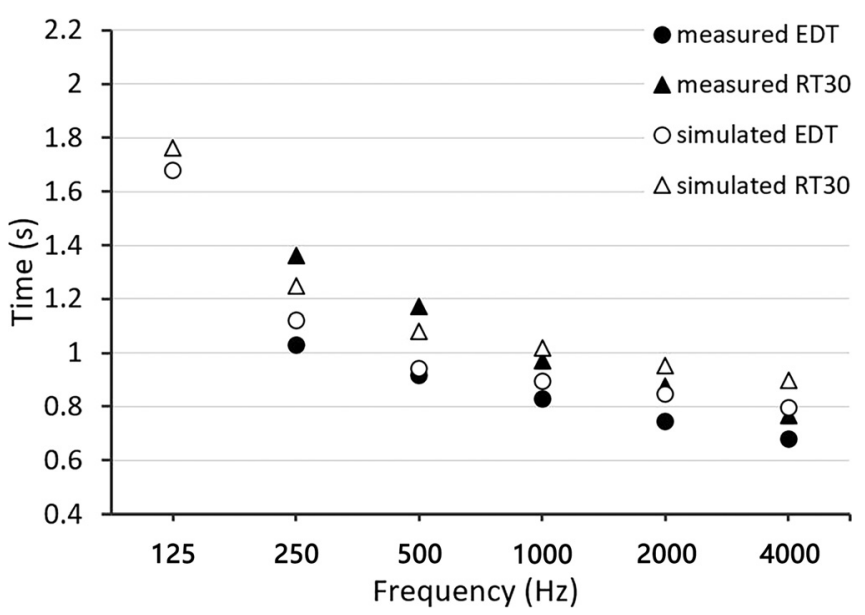

FIG. 7. Simulated and measured results of the reverberation time of the Main Hall of the Xiantong Temple.

reverberation time, however, to date, very few studies have attempted to determine suitable values for them in Main Halls. The Main Hall was treated as both a performance and religious space in this study. Churches and opera halls in European and American countries likely share similar acoustic environments with Main Halls. For these types of buildings, optimal mid-frequency reverberation time may be 1.4-1.6 s. ${ }^{44}$ Similarly, some studies have shown that in opera halls, the optimal mid-frequency reverberation time may be $1.4-1.8$ s. $^{45}$ Certainly, the Chinese Buddhist Main Hall differs greatly from Western churches and opera halls in terms of size and spatial layout. Various other studies have suggested that evaluations of the acoustic environments of Han Buddhist temples vary significantly from one person to another. ${ }^{30}$ Here, the indoor reverberation time of a Main Hall was used to analyze and objectively compare the sound field characteristics of Main Halls instead of directly evaluating the advantages or disadvantages of their sound fields.

To compare sound fields, three additional acoustic parameters were selected for reference- $C_{80}$, STI, and IACC. The parameter $C_{80}$ was used to describe the degree of music clarity and is expressed in dB. Typically, a longer reverberation time means a lower $C_{80}$ value and, consequently, a lower degree of music clarity. $C_{80}$ is usually measured as an average across the frequencies between $500 \mathrm{~Hz}$ and $1 \mathrm{kHz}$ and is denoted by $C_{80 \mathrm{~m}}$. It cannot be used to evaluate the acoustic quality of a hall, but can indicate whether the music is very clear or whether the reverberation time is extremely long. ${ }^{46}$ The STI is an objective parameter that indicates the quality of speech transmission and is associated with speech intelligibility with a value ranging from zero to one. In accordance with the international standard, if the STI value is above 0.75 , the speech intelligibility rating is "excellent." Values between 0.60 and 0.75 correspond to "good," between 0.45 and 0.60 correspond to "fair," between 0.30 and 0.45 correspond to "poor," and less than 0.30 correspond to "bad." 47

The IACC indicates the difference in sound that is audible to both ears and can be used to evaluate the spaciousness of sound. The IACC is measured at a position reached by sound within $80 \mathrm{~ms}$ after emission, usually expressed as an average over three frequencies (i.e., $500 \mathrm{~Hz}, 1 \mathrm{kHz}$, and $2 \mathrm{kHz}$ ), and denoted by $\mathrm{IACC}_{\mathrm{E} 3}$. A study of the acoustic quality of multiple concert halls demonstrated that the value of (1- $\left.\mathrm{IACC}_{\mathrm{E} 3}\right)$ has a positive correlation with the subjective sound evaluation by audiences and is a parameter that can be used as a reference to evaluate the acoustic quality of concert halls. $^{48}$

As a reference, the JND of each acoustic parameter are listed in Table II, and based on the findings of previous studies. ${ }^{21,35,49,50}$ In regard to the JND value for the STI index, Bradley et al. proposed that if an improvement produces less than a 0.1 increase in STI, it will probably not lead to an obvious improvement in conditions for speech, and if modifications to a room lead to no more than a 0.03 increase in STI, the effect will probably be inaudible. ${ }^{51}$

\section{RESULTS AND DISCUSSION}

An acoustic model for a Main Hall was constructed, and the related absorption and scattering coefficients for materials of the ancient Chinese buildings were correspondingly input. By changing the model settings, such as sound absorbers, Buddha statues, the spatial form of the roof, or sound source directivity, the changes of sound field parameters were analyzed to determine how the sound field in the Main Hall of a Han Buddhist temple was impacted by spatial elements and sound sources.

\section{A. Effects of fabric sound absorbers on the sound field}

The fabric sound absorbers in the Main Hall included those on the ground (e.g., kowtow cushions) and in the air (e.g., textile Buddhist ornaments such as curtains above the Buddha statues). When the nondirectional sound source S1 was set up and all of the fabric sound absorbers were removed, the following changes were noted: indoor reverberation time (Fig. 8), the indoor $T_{30 \mathrm{~m}}$ increased from $1.05 \mathrm{~s}$ to $1.39 \mathrm{~s}$ (increasing by $32.3 \%$ ), and the $\mathrm{EDT}_{m}$ increased from $0.92 \mathrm{~s}$ to $1.35 \mathrm{~s}$ (increasing by $46.8 \%$ ). These are far higher than the 5\% increases in JND values of the reverberation time. It is evident that the sound absorbers affected the indoor reverberation times.

TABLE II. JND for objective parameters.

\begin{tabular}{lcccccc}
\hline \hline Parameter & $G(0.5-1 \mathrm{kHz})$ & $\mathrm{RT}(0.5-1 \mathrm{kHz})$ & EDT $(0.5-1 \mathrm{kHz})$ & STI & $C_{80}(0.5-1 \mathrm{kHz})$ & IACC $\mathrm{E3}(0.5-2 \mathrm{kHz})$ \\
\hline $\mathrm{JND}$ & $1 \mathrm{~dB}$ & $5 \%$ & $5 \%$ & 0.03 & $1-\mathrm{dB}$ & 0.075 \\
\hline \hline
\end{tabular}




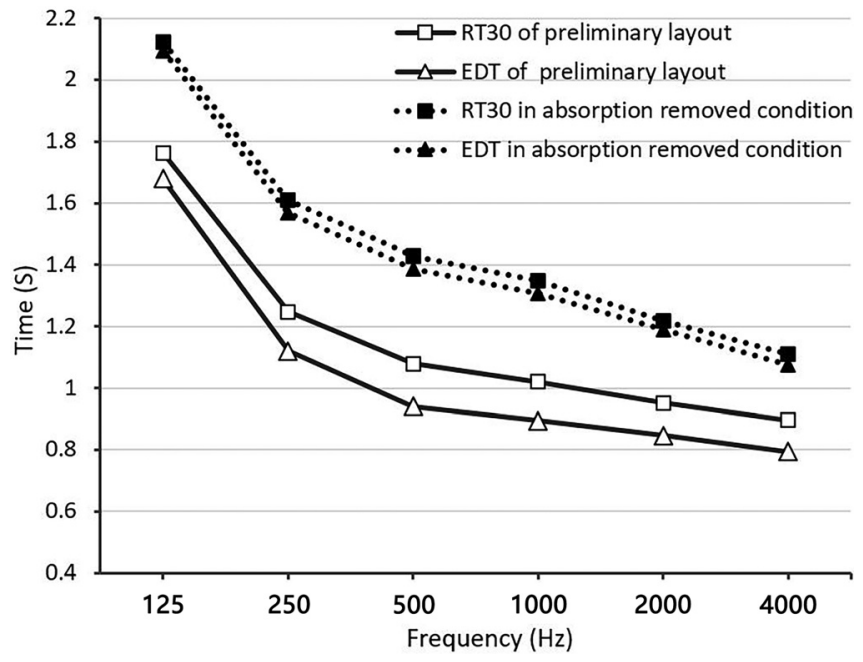

FIG. 8. Change in reverberation time in absence of sound absorbers.

After the fabric sound absorbers were removed, (1-IACC $\mathrm{E}_{\mathrm{E} 3}$ ) decreased from 0.648 to 0.486 . The difference of 0.162 is greater than 0.075 (the JND value of the $\mathrm{IACC}_{\mathrm{E} 3}$ ), indicating that the sound absorbers improved sound quality. The $C_{80 m}$ value decreased from 4.45 to $2.19 \mathrm{~dB}$, and the STI decreased from 0.58 to 0.53 . Note both differences exceed that of the corresponding change in the JND value. These changes reveal that the sound absorbers in the Main Hall could affect music clarity and speech intelligibility to a noticeable degree. The average $\operatorname{SPL}(A)$ value increased from 34.2 to $35.6 \mathrm{dBA}$, and the standard deviation of the SPL $(A)$ decreased from 1.30 to $1.24 \mathrm{dBA}$. Evidently, the sound absorbers did not affect the SPL significantly. In comparison, the sound absorbers in the air affected the sound field more significantly than those on the ground. When only the absorbers in the air were removed, the $T_{30 m}$ and $\mathrm{EDT}_{m}$ values increased by $17.3 \%$ and $25.1 \%$, respectively. However, when only the absorbers on the ground were removed, the $T_{30 m}$ and $\mathrm{EDT}_{m}$ values increased by $11.3 \%$ and $17.9 \%$, respectively. This reverberation time result was consistent with previous studies on conducted Venetian churches, which proposed that sound absorbers, such as wall tapestries, improved reverberation time in the church. ${ }^{3}$ Another relevant study provided an analysis of sound absorbers in the Indian Deekshabhoomi Stupa, ${ }^{19}$ where the mid-frequency reverberation time increased by $73.2 \%$ from occupied (5.6 s) to unoccupied $(9.7 \mathrm{~s})$ conditions. The Indian Stupa was different from the Chinese Buddhist Main Hall in terms of building volume, architecture structures, and indoor materials. The characteristics of the two sound fields varied considerably. The sound field in the Indian Stupa had a reverberation time greater than $5 \mathrm{~s}$, while that of the sound field in the Chinese Buddhist Main was less than $2 \mathrm{~s}$. This suggests that the Main Hall may be more appropriate for speech-related activities.

\section{B. Effects of Buddha statues on the sound field}

The Buddha statues, including the central Buddha statues at the center of the hall and the side Buddha statues on each side of the hall, act as both absorbers and diffusers.

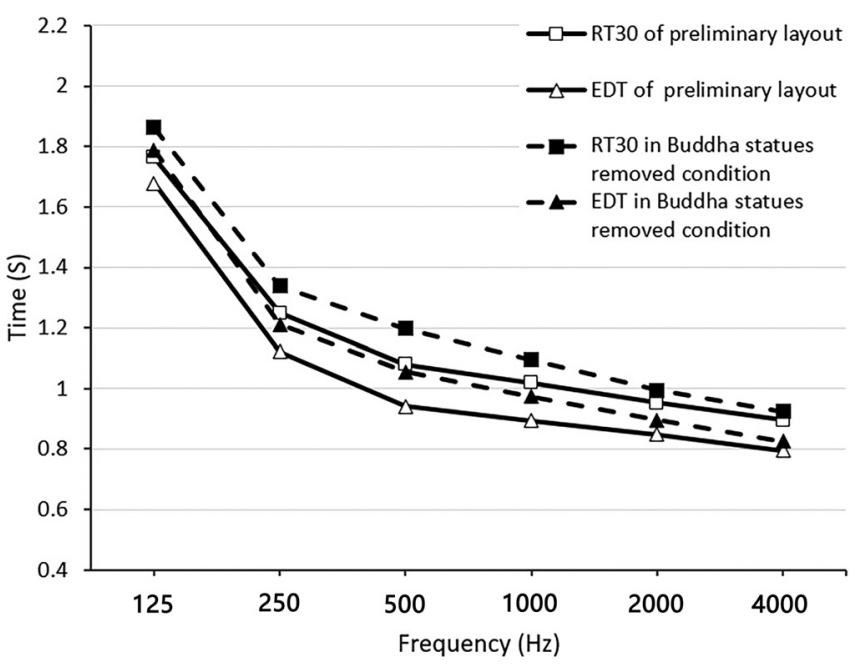

FIG. 9. Change in reverberation time in absence of Buddha statues.

Figure 9 illustrates the effects of the central and side Buddha statues on the sound field of the hall. When S1 was set up and all of the Buddha statues were removed, the average $T_{30 m}$ and $\mathrm{EDT}_{m}$ values increased by $9.2 \%$ and $10.6 \%$, respectively. Both are higher than the 5\% increases in JND values of reverberation time. This result corresponded with a previous study on indoor diffusers in architectural spaces. ${ }^{14}$ The central Buddha statues near the sound source, similar to the altars in the Japanese Buddhist temple, enhanced the early reflection. ${ }^{23}$ This reduced the chance of having a hollow, muddy, and poorly defined sound due to mitigated specularity and short echoes, thereby improving the acoustic quality of the room. ${ }^{14,16}$ The side Buddha statues also enhanced reflection near the lateral wall, which was equally important for the indoor sound field. ${ }^{15,23}$

At the same time, $\left(1-\mathrm{IACC}_{\mathrm{E} 3}\right)$ decreased by 0.07 , a difference approximating the JND value (0.075), confirming that the indoor acoustic quality decreased somewhat. The SPL increased by $0.43 \mathrm{dBA}$, and the standard deviation of the SPL decreased by $0.11 \mathrm{dBA}$. For mid-frequencies, the average SPL increased by $0.13 \mathrm{~dB}$, and the standard deviation of the SPL decreased by $0.03 \mathrm{~dB}$. Meanwhile, the STI decreased by 0.01 , and $C_{80 m}$ changed from $4.45 \mathrm{~dB}$ to $4.00 \mathrm{~dB}$. The values of these parameters varied slightly (all less than JND). Further analysis showed that the central Buddha statues affected the reverberation time more than the side Buddha statues. If only the central Buddha statues were removed, the $T_{30 m}$ and $\mathrm{EDT}_{m}$ increased by $5.4 \%$ and $6.5 \%$, respectively, while if only the side Buddha statues were removed, the $T_{30 m}$ and $\mathrm{EDT}_{m}$ increased by $2.1 \%$ and $3.8 \%$, respectively.

\section{Effects of the form of the roof on the sound field}

Traditional Main Halls are typically fitted with flush gable or gable-and-hip roofs, and some are internally fitted with flat suspended ceilings, which can also be interpreted as flat roofs. This study built three sound field models of a Main Hall with identical volumes but different types of 
roofs. The placement of the indoor objects (e.g., Buddha statues) was identical to the setup replicating the acoustic absorption coefficient. When $\mathrm{S} 1$ was set up, the reverberation time was longest with a flat roof. When the Main Hall with a flush gable or gable-and-hip roof was analyzed, the $T_{30 \mathrm{~m}}$ decreased by $4.26 \%$ and $5.07 \%$, the EDT $_{m}$ decreased by $1.97 \%$ and $4.02 \%$, the STI increased by 0.008 and 0.011 , the $C_{80 \mathrm{~m}}$ increased by $0.27 \mathrm{~dB}$ and $0.54 \mathrm{~dB},\left(1-\mathrm{IACC}_{\mathrm{E} 3}\right)$ increased by 0.012 and 0.041 , and the SPL decreased by $0.03 \mathrm{dBA}$ and 0.05 $\mathrm{dBA}$, respectively. The variation in both the average and standard deviation of the $\mathrm{SPL}_{m}$ were less than $0.11 \mathrm{~dB}$. Almost every difference is less than the JND value. For traditional Main Halls of the same size and building materials, the form of the roof did not significantly affect the sound field. The possible cause being that although the shape of the roof changed, the indoor space was regular and the main walls, which reflect sound waves, were still parallel. Thus, the sound field changed little as compared to when the room shape became irregular. ${ }^{20}$ The result of this study is consistent with previous findings for several Romanesque churches, which demonstrated that no significant correlation was found between reverberation times and the geometric parameters. ${ }^{11}$

Given the same architecture, the indoor sound field varied with or without a flat suspended ceiling because of the change in spatial volume and the ceiling materials. Figure 10 illustrates the interior of the Main Hall with and without a flat suspended ceiling. Both roof materials were wooden; however, the wooden surface of the flat suspended ceiling was relatively smooth due to painting and its decoration. The wooden surface of the pitched roof was generally natural and rough, and structural elements, such as the beam and purlin, were exposed. Figure 11 illustrates the variation in the reverberation time using the acoustic model for the Xiantong Temple. If the suspended ceiling was removed, the average values of the $T_{30 m}$ and $\mathrm{EDT}_{m}$ decreased by $0.134 \mathrm{~s}$ and $0.127 \mathrm{~s}(12.7 \%$ and $13.9 \%)$, respectively, the $C_{80 m}$ increased by $1.26 \mathrm{~dB}$, and $\left(1-\mathrm{IACC}_{\mathrm{E} 3}\right)$ decreased by 0.084. All of these values were higher than the JND. Previous studies have proposed that, compared with the vaulted roofs in churches, the flat wooden or painted canvas ceiling would cause a significant reduction in reverberation time (previous studies in six churches in Italy and Spain have shown that STI values were often in the "poor" rating range for reverberation times that were too $\operatorname{long}^{22}$ ), and would improve the acoustic environment in the churches. ${ }^{4,5}$ However, the results of this study determined that a flat suspended ceiling in the Buddhist Main Hall might increase the reverberation time. A possible explanation for this inconsistency is that the wooden ceiling in churches might increase sound absorption and/or reduce volume. Indeed, volume and materials were the most important factors affecting reverberation time in churches. ${ }^{11}$ In the Chinese Buddhist Main Hall, the complex sloping roof structure with its rough material could cause the sound absorption and scattering coefficients to be larger than those of the flat wooden ceiling. Thus, when a flat wooden ceiling was set in the Buddhist Hall, the impact of increased reverberation time caused by

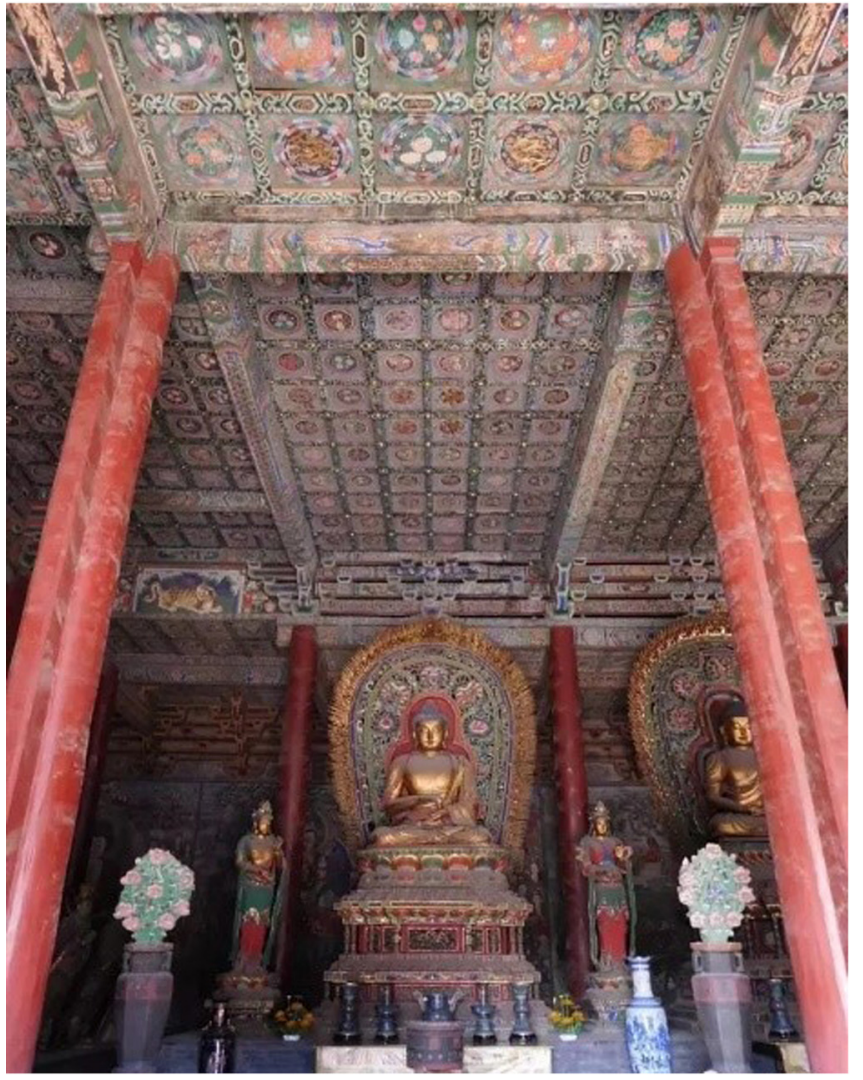

Main hall with the flat suspended ceiling.

(a)

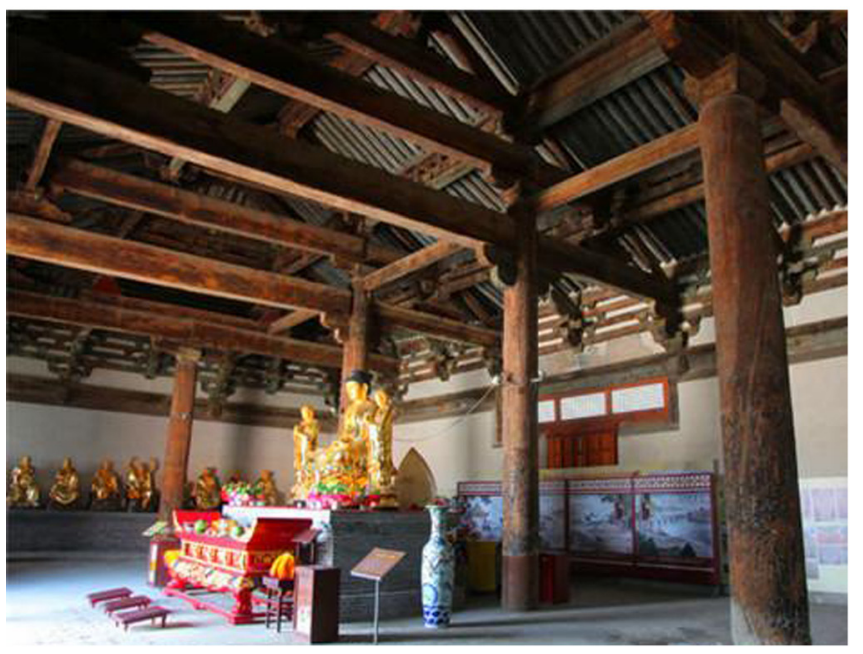

Main hall without the flat suspended ceiling.

(b)

FIG. 10. (Color online) Indoor picture of the Main Hall, including (a) with the flat suspended ceiling and (b) without the flat suspended ceiling.

reduced sound absorption and reflection could have exceeded the impact of the decreased reverberation time caused by the reduced volume. The overall conclusion was that a suspended ceiling increased the indoor reverberation time and affected acoustic quality and music clarity.

After the suspended ceiling was removed, the $\operatorname{SPL}(A)$ decreased by $0.24 \mathrm{dBA}$, while the average $\mathrm{SPL}_{m}$ decreased 
JASA

https://doi.org/10.1121/10.0000758

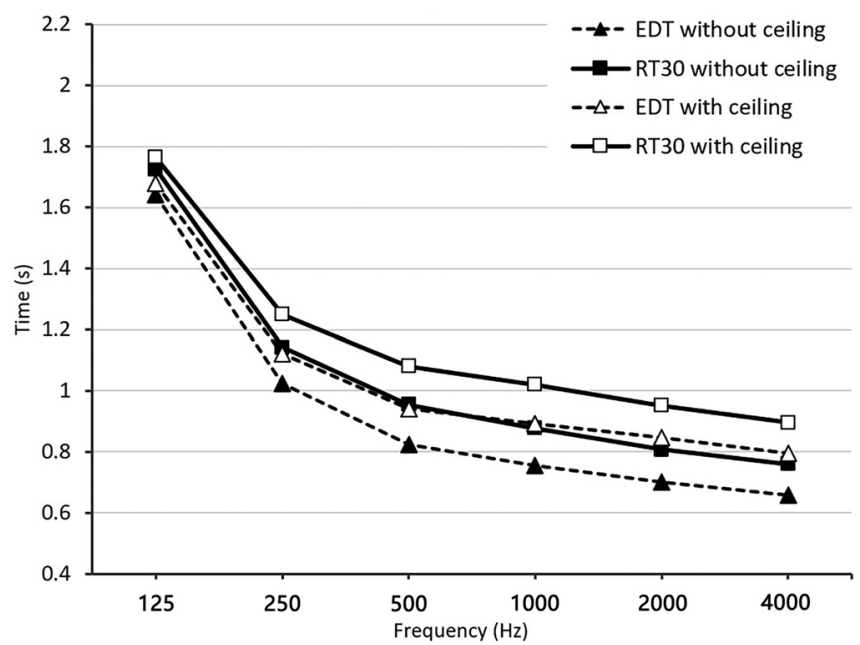

FIG. 11. Effects of a suspended ceiling on reverberation time.

by $0.79 \mathrm{~dB}$. The STI increased by 0.025 . These values were lower than the JND. This evidence suggests that the suspended ceiling had no significant effect on the SPL or speech intelligibility.

\section{Effects of directivity and locations of sound sources on the sound field}

The chanting generated by monks in the Main Hall was a directional sound source. Represented by source S2, as illustrated in Fig. 5(c), sound was sent in four directions: S2D1, S2D2, S2D3, and S2D4. From the simulations of the four modes, the variation in the $T_{30 \mathrm{~m}}$ of the indoor receivers was less than $0.03 \mathrm{~s}$ (less than 2\%), which is negligible. Figure 12 illustrates the average EDT of each receiver. The $\mathrm{EDT}_{m}$ was minimized $(0.91 \mathrm{~s})$ in the S2D1 direction, while it was $1.03 \mathrm{~s}$ toward the S2D2, $1.12 \mathrm{~s}$ toward the S2D3, and $0.97 \mathrm{~s}$ toward the S2D4, increasing by $12.5 \%, 22.7 \%$, and $6.2 \%$, respectively, as compared with those in the S2D1

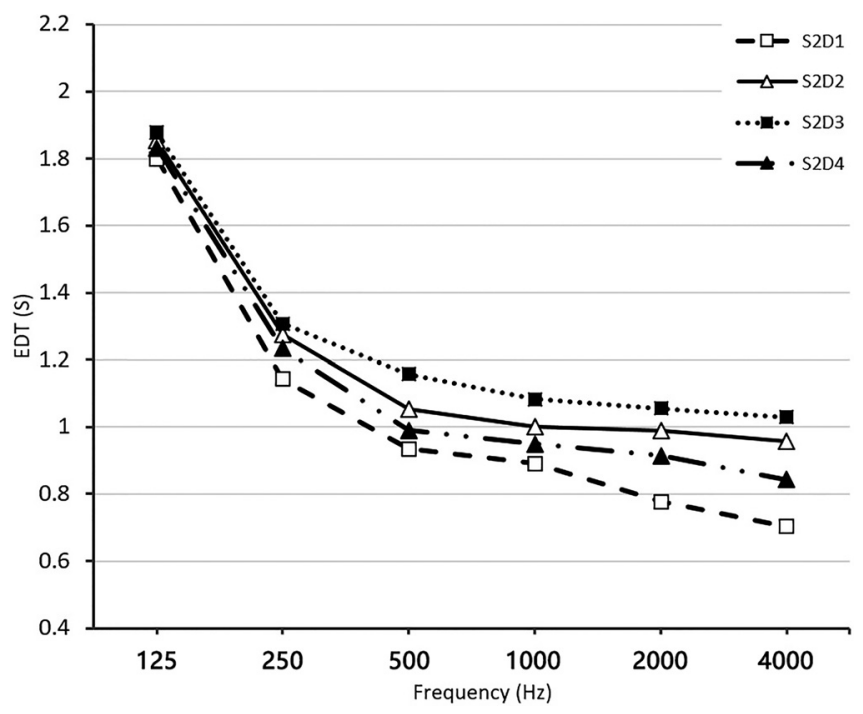

FIG. 12. Effects of directivity of sound source S2 on EDT. direction. Seemingly, the $\mathrm{EDT}_{m}$ rather than the $T_{30 m}$, was primarily affected by the directivity of the sound sources in the Main Hall.

The STI was highest $(0.58)$ in the S2D1 direction and decreased by 0.07 (S2D2), 0.11 (S2D3), and 0.04 (S2D4) compared with the S2D1 direction. In the S2D1 direction, when the monks stood face-to-face to chant, speech intelligibility was the highest. In the S2D3 direction, when the monks had their backs to the receivers when chanting, speech intelligibility was the lowest. This result is consistent with previous studies on churches and Japanese temples, which showed that source direction clearly affected STI, and vocal projection toward the congregation was more intelligible. ${ }^{1,22-24}$ Figure 13 illustrates a simulation diagram for the STI in the S2D1 and S2D3 directions.

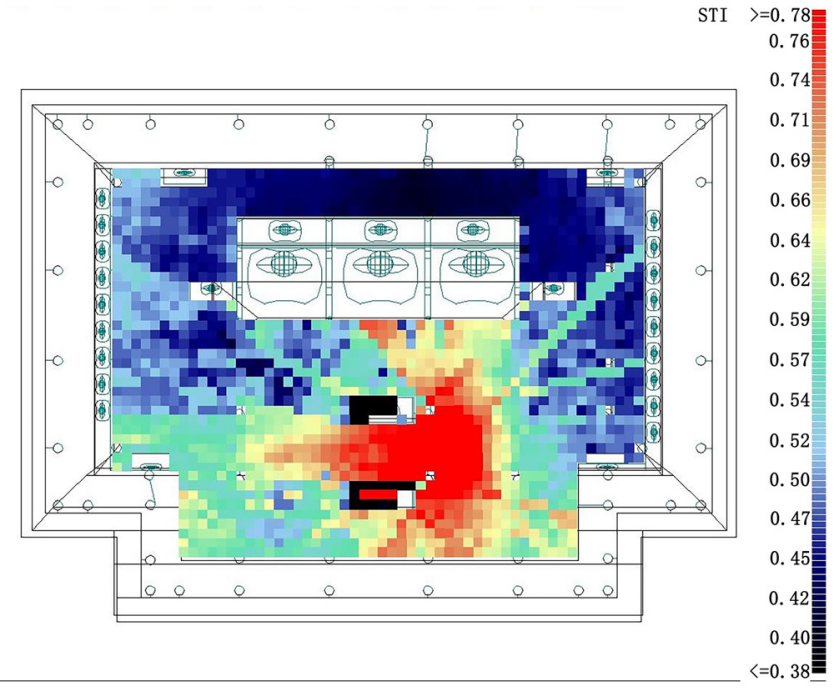

S2D1

(a)

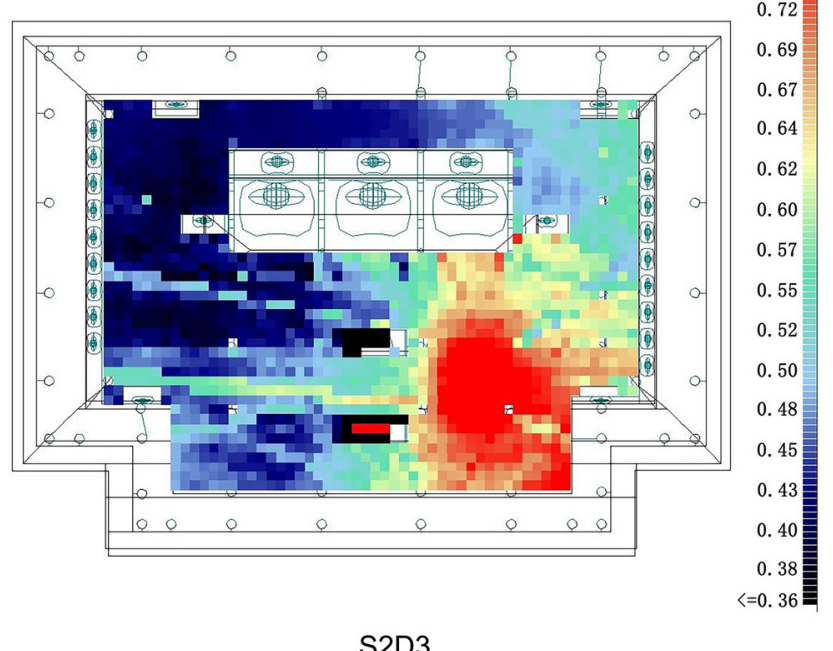

(b)

FIG. 13. (Color online) Effects of directivity of sound sources on STI. (a) S2D1, (b) S2D3. 
$C_{80 m}$ was the highest $(4.90 \mathrm{~dB})$ toward the S2D1, lowest $(1.33 \mathrm{~dB})$ toward the S2D3, $3.46 \mathrm{~dB}$ toward the S2D2, and $4.08 \mathrm{~dB}$ toward the S2D4. Thus, music clarity and speech intelligibility were highest when the monks chanted sutras face-to-face. The average SPL $(A)$ of the receivers was highest in the S2D1 direction and lowest in the S2D3 direction. The difference of $\operatorname{SPL}(A)$ between them was $2.15 \mathrm{dBA}$ (and $3.15 \mathrm{~dB}$ under mid-frequencies). In the four directions, the variation in the standard deviation of $\operatorname{SPL}(A)$ was less than $0.60 \mathrm{dBA}$ (less than $0.90 \mathrm{~dB}$ under mid-frequencies). The directivity of the sound sources had no significant effect on (1-IACC $\left.\mathrm{I}_{\mathrm{E} 3}\right)$. When the (1-IACC $\left.\mathrm{E}_{\mathrm{E} 3}\right)$ averages of calculated results from the eight receivers were compared in the cases of the four different sound source directions, the difference between its maximum and minimum values was less than JND. This result is not consistent with previous studies, which indicated that sound source direction had a clear effect on the IACC in Japanese temples, ${ }^{23}$ and also had a clear effect on IACC at higher frequencies (2000 and $4000 \mathrm{~Hz}$ ) in Japanese churches. ${ }^{24}$ One possible reason is that the calculated results of $\left(1-\mathrm{IACC}_{\mathrm{E} 3}\right)$ are mainly based on mid-frequency $(500,1000 \mathrm{~Hz})$ and $2000 \mathrm{~Hz}$ values, and in different directions, as illustrated in Fig. 6(a), the sound pressure change in terms of directional sound sources in the mid-frequency is less than the change in the high frequency, so the impact of the sound source directivity on (1-IACC $\left.\mathrm{E}_{\mathrm{E} 3}\right)$ is smaller than on IACC, for which calculated results include high frequency values. Another possible reason is that the spatial layout in the Chinese Buddhist Main Hall is different from the layouts in Japanese churches and Japanese Buddhist temples. Thus, there are more diffusers (including the central and side Buddha statues) in the Chinese Buddhist Main Hall, and therefore the sound field characteristics in the Chinese Buddhist Main Hall differ from those in Japanese religious buildings.

The variation in the values of the indoor sound field parameters with the locations of the sound sources was analyzed. For nondirectional sources, S1 was placed at the center of the hall, and S3 was placed on one side of the hall. Compared with S1, the $\mathrm{EDT}_{m}$ of S3 increased from $0.92 \mathrm{~s}$ to $1.01 \mathrm{~s}(9.8 \%)$, the STI of S3 decreased from 0.58 to 0.53 , and $\left(1-\mathrm{IACC}_{\mathrm{E} 3}\right)$ decreased from 0.648 to 0.572 . These values were all greater than the JND. These data demonstrate that the sound source set up at the center of the hall has some positive effect on speech intelligibility. Note that also located at position $\mathrm{S} 1$ were the primary musical instruments as well as a core monk who led the chanting. When S3 was set up, the $T_{30 m}$ increased by $0.01 \mathrm{~s}$, the average $\operatorname{SPL}(A)$ decreased by $1.9 \mathrm{dBA}$ ( $\mathrm{SPL}_{m}$ decreased by $2.3 \mathrm{~dB}$ under mid-frequencies), and $C_{80 \mathrm{~m}}$ decreased from $4.45 \mathrm{~dB}$ to $3.70 \mathrm{~dB}$. These values did not vary significantly. The locations of the sound sources affected the sound field in the Main Hall to a certain extent. This result is similar to a previous study on sound source location in Japanese Buddhist temples, ${ }^{23}$ possibly because in the Main Hall sound reflections caused by the Buddha statues act as diffusers (corresponding to the altar, and the like, in Japanese Buddhist

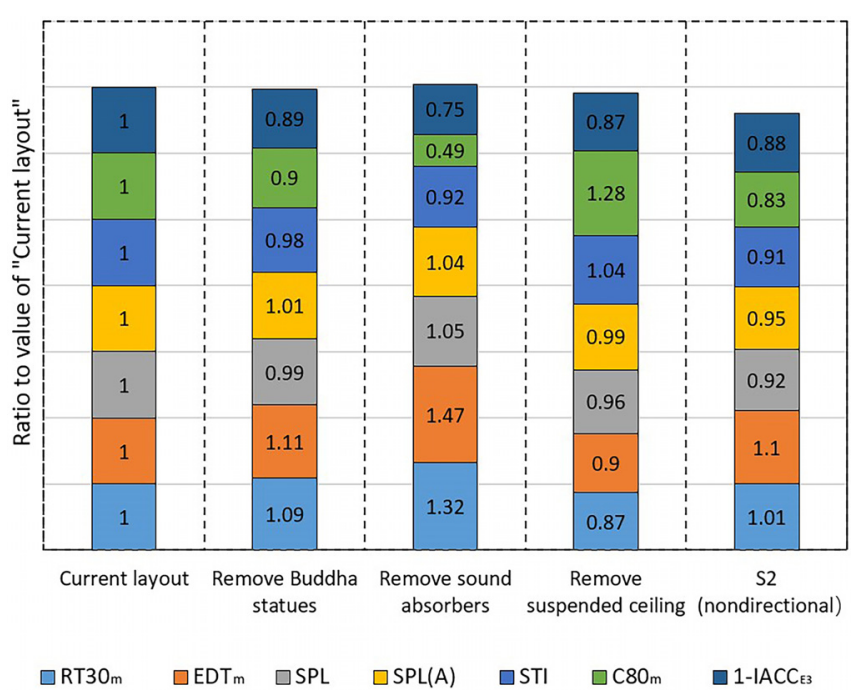

FIG. 14. (Color online) Simulated results after current layout and sound field elements were changed.

temples). The resulting reflections would change because of the different locations of the sound sources, thus, affecting the indoor reverberation components and binaural coherence. Yet, another previous study suggests that sound source location in Japanese churches had a relatively small effect on sound field parameters. ${ }^{24}$ This may be because there were no similar diffusers, such as Buddha statues, near the sound source.

The nondirectional sound source S1 was set up in the current complete indoor layout in the Main Hall, and the values of the acoustic parameters were set to one. Figure 14 illustrates the resulting ratios of the simulated values of the acoustic parameters after the spatial elements and locations of the sound sources that affected the sound field were changed.

\section{CONCLUSIONS}

This paper analyzed the acoustic characteristics in the Main Hall of a Han Buddhist temple. First, the sound fields of three traditional Chinese halls were measured, and the acoustic parameter values were determined using acoustic simulation software. Next, an indoor acoustic model for a typical Main Hall (the Main Hall of the Xiantong Temple in Mount Wutai) was created, and the effects of indoor spatial elements and the directivity and locations of sound sources on the indoor sound field were analyzed. The findings of this study can be summarized as follows:

(1) The spatial elements in the Main Hall had a clear effect on the indoor sound field. After various fabric sound absorbers (e.g., curtains, pennants, and cushions) in the Main Hall were removed, the reverberation time increased significantly, the $T_{30 \mathrm{~m}}$ increased by $32.3 \%$, and the $\mathrm{EDT}_{m}$ increased by $46.8 \%$. After the central and side Buddha statues, which acted as sound absorbers and diffusers, were removed from the Main Hall, the reverberation time also slightly increased. In addition, the fabric sound absorbers and Buddha statues had some 
positive effect on speech intelligibility and sound spaciousness but did not significantly affect the indoor SPLs.

(2) The form of the roof of the Main Hall did not significantly affect the indoor SPL or reverberation time. Data suggested that a flat suspended ceiling installed within the Main Hall might slightly increase the reverberation time.

(3) The directivity of the sound sources inside the Main Hall clearly affected the indoor sound field. When monks in the Main Hall stood face-to-face to chant, the $\mathrm{EDT}_{m}$ was minimized and the STI was maximized. In the three other directions tested, the $\mathrm{EDT}_{m}$ increased by $12.5 \%, 22.7 \%$, and $6.2 \%$, and the STI decreased by $0.07,0.11$, and 0.04 . The locations of the sound sources inside the Main Hall affected the $\mathrm{EDT}_{m}$ of the sound field and speech intelligibility to an observable degree.

In summary, in the Main Hall of a Han Buddhist temple, the central and side Buddha statues and the fabric elements (Buddhist ornaments and cushions) affected the indoor sound field to a discernable degree. The locations and directivity of the sound sources also affected the indoor sound field, whereas the form of the roof did not significantly affect the indoor sound field.

\section{ACKNOWLEDGMENTS}

The work was financially supported by National Natural Science Foundation of China (Grant No. 51678117).

${ }^{1}$ D. Liu, "The spatial attributes and basic forms of Chinese traditional courtyards," Lit. Art Stud. 2, 125-135 (1986) (in Chinese).

${ }^{2}$ D. Zhang, D. Liu, and J. Kang, Soundscape in Han Chinese Buddhist temples (China Architecture and Building, Beijing, 2018), Chap. 2, pp. 15-57 (in Chinese).

${ }^{3}$ B. Boren, M. Longair, and R. Orlowski, "Acoustic simulation of renaissance Venetian churches," J. Acoust. Soc. Am. 130, 17-27 (2011).

${ }^{4}$ J. Navarro, J. J. Sendra, and S. Muñoz, "The Western Latin church as a place for music and preaching: An acoustic assessment," Appl. Acoust. 70(6), 781-789 (2009).

${ }^{5}$ E. Cirillo and F. Martellotta, "Acoustics of Apulian-Romanesque churches: An experimental survey," Build. Acoust. 9(4), 271-288 (2002).

${ }^{6} \mathrm{~F}$. Martellotta and E. Cirillo, "Experimental studies of sound absorption by church pews," Appl. Acoust. 70(3), 441-449 (2009).

${ }^{7}$ A. Alonso and F. Martellotta, "Room acoustic modelling of textile materials hung freely in space: From the reverberation chamber to ancient churches," J. Build. Perform. Simul. 9(5), 469-486 (2016).

${ }^{8} \mathrm{~F}$. Martellotta and M. Castiglione, "On the use of paintings and tapestries as sound absorbing materials," in Forum Acusticum 2011 (2011).

${ }^{9}$ F. Martellotta, M. D'alba, and S. D. Crociata, "Laboratory measurement of sound absorption of occupied pews and standing audiences," Appl. Acoust. 72(6), 341-349 (2011).

${ }^{10}$ F. Martellotta, S. Della Crociata, and M. D'Alba, "On site validation of sound absorption measurements of occupied pews," Appl. Acoust. 72(12), 923-933 (2011).

${ }^{11}$ E. Cirillo and F. Martellotta, "Acoustics of Apulian-Romanesque churches: Correlations between architectural and acoustical parameters," Build. Acoust. 10(1), 55-76 (2003).

${ }^{12}$ V. Desarnaulds, A. P. O. Carvalho, and G. Monay, "Church acoustics and the influence of occupancy," Build. Acoust. 9(1), 29-47 (2002).

${ }^{13}$ S. Girón, L. Álvarez-Morales, and T. Zamarreño, "Church acoustics: A state-of-the-art review after several decades of research,” J. Sound. Vib. 411, 378-408 (2017).
${ }^{14}$ S. S. Utami, "Characterizing the audibility of sound field with diffusion in architectural spaces," Dissertation, University of Michigan, Ann Arbor, MI (2012).

${ }^{15}$ M. Barron, Auditorium Acoustics and Architectural Design, second ed. (Spon, New York, 2010), Chap. 4, pp. 75-127.

${ }^{16} \mathrm{P}$. D'Antonio and T. J. Cox, "Diffusor application in rooms," Appl. Acoust. 60(2), 113-142 (2000)

${ }^{17}$ U. Berardi, "Simulation of acoustical parameters in rectangular churches," J. Build. Perform. Simul. 7(1), 1-16 (2014).

${ }^{18}$ A. P. Carvalho, A. E. Morgado, and L. Henrique, "Relationships between subjective and objective acoustical measures in churches," Build. Acoust. 4(1), 1-20 (1997).

${ }^{19}$ M. Manohare, A. Dongre, and A. Wahurwagh "Acoustic characterization of the Buddhist temple of Deekshabhoomi in Nagpur, India," Build. Acoust. 24(3), 193-215 (2017).

${ }^{20} \mathrm{~K}$. Sato and M. Koyasu, "The effect of the room shape on the sound field in rooms (studies on the measurement of absorption coefficient by the reverberation chamber method I)," J. Phys. Soc. Jpn. 14(3), 365-373 (1959).

${ }^{21}$ L. Alvarez-Morales, T. Zamarreno, S. Giron, and M. Galindo, "A methodology for the study of the acoustic environment of Catholic cathedrals: Application to the Cathedral of Malaga," Build. Environ. 72,102-115 (2014).

${ }^{22}$ L. Alvarez-Morales and F. Martellotta, "A geometrical acoustic simulation of the effect of occupancy and source position in historical churches," Appl. Acoust. 91, 47-58 (2015)

${ }^{23}$ Y. Soeta, R. Shimokura, Y. H. Kim, T. Ohsawa, and K. Ito, "Measurement of acoustic characteristics of Japanese Buddhist temples in relation to sound source location and direction," J. Acoust. Soc. Am. 133, 2699-2710 (2013).

${ }^{24}$ Y. Soeta, K. Ito, R. Shimokura, S. Sato, T. Ohsawa, and Y. Ando, "Effects of sound source location and direction on acoustic parameters in Japanese churches," J. Acoust. Soc. Am. 131, 1206-1220 (2012).

${ }^{25} \mathrm{X}$. Yang (the Northern Wei Dynasty), The Records of Qielan at Luoyang, translated by R. Shang (Chuang Hwa Book Company, Beijing, 2012), pp. 4-9 (in Chinese).

${ }^{26}$ D. Zhang, D. Liu, and J. Kang, "Soundscape of bells in Chinese Buddhist temples," Architect. J. 11, 148-153 (2014) (in Chinese).

${ }^{27} \mathrm{Q}$. Tian, Pure Land Holy Music: Tian Qing Musicology Research Collection (Shandong Publishing House of Literature and Art, Jinan, 2002), pp. 332-365 (in Chinese).

${ }^{28} \mathrm{~J}$. Yuan, Music Culture of the Han Chinese Buddhism (Communication University of China Press, Beijing, 2000), pp. 34, 51, 88 (in Chinese).

${ }^{29}$ J. Ge, M. Guo, and M. Yue, "Soundscape of the West Lake scenic area with profound cultural background-A case study of Evening Bell Ringing in Jingci Temple, China," J. Zhejiang Univ. Sci. A: Appl. Phys. Eng. 14(3), 219-229 (2013).

${ }^{30}$ D. Zhang, M. Zhang, D. Liu, and J. Kang, "Soundscape evaluation in Han Chinese Buddhist temples,” Appl. Acoust. 111, 188-197 (2016).

${ }^{31}$ D. Zhang, M. Zhang, D. Liu, and J. Kang, "Sounds and sound preferences in Han Buddhist temples," Build. Environ. 142, 58-69 (2018).

${ }^{32}$ L. Pon, S. C. Douglas, and F. Martellotta, "Sound absorption measurements under strongly non-diffuse conditions: The case of the Pastrana Tapestries at Meadows Museum in Dallas," Acta Acust. Acust. 102(5), 955-962 (2016).

${ }^{33} \mathrm{~J}$. Yu and M. Sun, "The interior and furniture in Ningqing Palace of Shengyang Forbidden City," Furniture 05, 89-92 (2007) (in Chinese).

${ }^{34} \mathrm{Wu}$, B., A Study on Mukden Palace in the Qing Dynasty (Liaoning University Publishing House, Shenyang, 2007) (in Chinese).

${ }^{35}$ C. L. Clause, K. George, and G. Juan, "Odeon Room Acoustics Program, version 13," User manual, Industrial, Auditorium and Combined Editions (2016), pp. 20-42.

${ }^{36} \mathrm{Q}$. Peng and R. Fu, "Computer acoustic simulation ODEON software and its application," China New Technol. Prod. 172(6), 44 (2010) (in Chinese).

${ }^{37}$ C. M. Harris (ed.), Handbook of Noise Control, 2nd ed. (McGraw-Hill, New York, 1991).

${ }^{38}$ X. Liu, Building Physics, third ed. (China Architecture and Building, Beijing, 2011), pp. 506-507 (in Chinese).

${ }^{39} \mathrm{~S}$. Wu, Architectural Acoustics Design Principles (China Architecture and Building, Beijing, 2000), pp. 217-219 (in Chinese). 
${ }^{40}$ J. Liu, Building Physics, fourth ed. (China Architecture and Building, Beijing, 2009), pp. 540, 543 (in Chinese).

${ }^{41} \mathrm{X}$. Zhong, Building Sound Absorbing Material and Sound Insulation Material (Chemical Industry, Beijing, 2005), p. 310 (in Chinese).

${ }^{42} \mathrm{~J}$. Ge and S. Wu, "The evolution of ancient Chinese theatres and the achievements of sound quality design," J. Zhejiang Univ. 11(1), 136-141 (1997) (in Chinese).

${ }^{43}$ A. H. Marshall and J. Meyer, "The directivity and auditory impressions of singers," Acta Acust. Acust. 58, 130-140 (1985).

${ }^{44} \mathrm{~J}$. Cowan, Architectural Acoustics Design Guide, translated by J. Li (China Architecture and Building, Beijing, 2004), p. 25 (in Chinese).

${ }^{45}$ L. Cremer and H. A. MuIIer, Principles of Indoor Acoustic Design and Application, translated by J. Wang (Tongji University Press, Shanghai, 1995), p. 386 (in Chinese).
${ }^{46} \mathrm{~F}$. Martellotta, "The just noticeable difference of center time and clarity index in large reverberant spaces," J. Acoust. Soc. Am. 128, 654-663 (2010).

${ }^{47}$ ISO 9921, "Ergonomics-Assessment of speech communication" (International Organization for Standardization, Geneva, Switzerland, 2003).

${ }^{48}$ T. Hidaki, L. L. Beranek, and T. Okano, "Interaural cross-correlation, lateral fraction, and low- and high-frequency sound levels as measures of acoustical quality in concert halls," J. Acoust. Soc. Am. 98, 988-1007 (1995).

${ }^{49}$ ISO 3382-1, "Acoustics-Measurement of room acoustic parametersPart 1: Performance spaces" (International Organization for Standardization, Geneva, Switzerland, 2009).

${ }^{50} \mathrm{~T}$. Okano, "Judgments of noticeable differences in sound fields of concert halls caused by intensity variations in early reflections," J. Acoust. Soc. Am. 111, 217-229 (2002).

${ }^{51}$ J. S. Bradley, R. Reich, and S. G. Norcross, "A just noticeable difference in C50 for speech,” Appl. Acoust. 58(2), 99-108 (1999). 